\title{
ON THE BEST METHOD OF DEMAGNETIZING IRON IN MAGNETIC TESTING.
}

\author{
By Charles W. Burrows.
}

The magnetic permeability of a specimen of iron is a function of its previous mechanical, thermal, and magnetic history as well as of its chemical composition. While therefore the magnetic permeability of a given piece of metal may be measured quite accurately at a given instant, in general the very process of measurement adds a new chapter to the history of the metal and may leave it with magnetic properties different from those it had at the beginning of the test. Such a test may be quite misleading as regards the real magnetic properties of the specimen. Hence we are most concerned with those properties and conditions that can be associated and reproduced. Some little space will therefore be devoted to the consideration of the after effects of various details in the history of the magnetic substance, and a plan will be outlined whereby a specimen may be freed from all effects of previous magnetic treatment, and so be brought to a standard condition. We shall thus define a set of normal conditions and specifications under which the specimen is to be tested. When this is done, the permeability becomes a definite physical constant, and may be redetermined at will. All numerical quantities and equations are given in the electromagnetic c. g. s. system of units. Field strength and induction per square centimeter are expressed as so many units, although many writers prefer the more distinctive term gauss.

\section{THE RESULTS OF EARLIER OBSERVERS.}

Considerable work on the influence of previous magnetic treatment and certain other related details on the value of the induction has been done and some of the more important conclusions are here 
given. Ewing in his classic work "Magnetic Induction in Iron and other Metals," third edition, I900, has recorded the following phenomena, most of which are founded on magnetometric measurements either by himself or by earlier investigators.

(I) Demagnetization by hand reversals or by rotating commutator is complete if the maximum current is at least as great as the greatest used since the last demagnetization. ${ }^{1}$

(2) If a force is repeatedly applied and removed, the values of the induction and the residual magnetism form two increasing sequences of numbers whose last terms approach each other. ${ }^{2}$ This has been called "molecular accommodation."

(3) During repeated reversals of the same magnetizing force, the change of induction on reversal gradually becomes smaller and finally reaches a constant value. ${ }^{3}$

(4) After the change of induction on slow reversal of current has become constant, a sudden reversal will at first increase the change of induction on reversal, but later reversals make this change smaller than ever. ${ }^{3}$

(5) After application of an intense magnetizing force the tendency to a diminution of the change of induction on repeated reversal of a given magnetizing force has disappeared. ${ }^{4}$

(6) "Creeping" produces a greater induction than is at first shown on the application of the magnetizing force. ${ }^{5}$

In an article entitled "Studies in Magnetic Testing," ${ }^{6}$ Professor Searle gives the results of an extended investigation carried out at the Cavendish Laboratory. An alternating current of 90 cycles controlled by a liquid rheostat furnished the demagnetizing force. Inductions were measured ballistically. The specimens used were samples of transformer iron $4 \mathrm{~cm}$ wide, $68.8 \mathrm{~cm} \mathrm{long}$, and about $0.035 \mathrm{~cm}$ thick, and were so arranged that the magnetic circuit was

\footnotetext{
${ }^{1}$ Magnetic Induction, etc., p. 46.

${ }^{2}$ Fromme, Pogg. Ann. Ergbd., 7; I875. Wied. Ann., 4; 1878.

${ }^{3}$ Magnetic Induction, etc., p. 340. My experience seems to indicate that this later decrease is nothing more than a part of the original decrease accelerated perhaps by the sudden reversal.

${ }^{4}$ Magnetic Induction, etc., p. 34r. This does not accord with my experience, and is therefore probably found only in certain specimens.

${ }^{5}$ Ewing, Phil. Trans., p. 569, I885.

${ }^{6}$ G. F. C. Searle, Proc. of Inst. of Elect. Engrs., Part I7o, 34, pp. 55-II8; 1904.
} 
a square about $50 \mathrm{~cm}$ on a side. The more important conclusions of this paper are here given.

(I) Complete demagnetization is obtained by an alternating current with a frequency of 90 cycles per second, provided the initial demagnetizing force is greater than a certain "critical value."

(2) An imperfect demagnetization results in a lower apparent induction.

(3) The effect of many reversals of a force $H_{y}$ on the apparent induction due to a small force $H=\mathrm{I}$ is modified by many reversals of a force $H_{x}$ as follows:

(a) If $H_{x}$ is as large as the critical value, it wipes out the effect of $H_{y}$ and leaves its own after effect.

(b) If $H_{x}$ is less than the critical value its effect in raising the apparent induction is less as $H_{y}$ is greater. In every case it leaves its own after effect.

(c) If $H_{x}$ is very small, less than one, the after effect in certain cases is to give a lower apparent induction than if $H_{x}$ were omitted. ${ }^{7}$

(d) If $H_{y}=0$ the apparent induction may be raised by a small value of $H_{x}{ }^{8}$

(4) Many reversals of a force $H_{x}$ cause a lowering of the apparent induction due to a smaller force $H_{o}$, and the lowering increases with $H_{x}$.

(5) A constant force superposed upon the force used in determining the induction reduces the apparent induction. A constant force of $H=0.2$ in one case caused a 20 per cent reduction for low values of $B .^{9}$

(6) Virgin iron gives lower values of the apparent induction than demagnetized iron in the lower values of $B$. In the upper regions the difference disappears. This iron, although it is called virgin because it had experienced no other magnetizing force than the

${ }^{7}$ I have not attempted to verify this. It seems analogous to the decrease in apparent induction noted in some cases when the upper limit of the demagnetizing force was too low.

${ }^{8}$ This is contrary to my experience.

${ }^{9} \mathrm{I}$ have noticed a lowering of the apparent induction when the specimen was turned so that the earth's field was parallel to its length.

I $737-07-3$ 
earth's field, showed a small initial induction even after careful annealing. ${ }^{10}$

All of the above conclusions have been carefully examined during the present investigation and have been verified except in certain cases, particularly that on the efficiency of demagnetization by alternating current, which will be discussed latter. While these general conclusions do not cover exactly the same ground as the present work yet, with an exception or two, there are no inconsistencies between the earlier work and my own.

\section{DEFINITIONS.}

In Fig. I, $B$ and $H$ are the magnetic induction per square centimeter and magnetizing force, respectively. Then if we start with a piece of virgin iron and apply successively increasing magnetizing forces and note the corresponding inductions, we get a series of points having the line OA as locus. If the magnetizing forces had been negative instead of positive, the symetrical curve OB would have been traced. The positive branch of the curve is commonly called the ascending $B-H$ curve, or simply the ascending curve. Consider the point $\mathrm{A}$ on the ascending curve and the corresponding point $B$ on the negative curve. In the course of the ascending curve let the magnetizing force be reversed at the point $\mathrm{A}$. This will cause the point which represents the magnetic state of the iron, or state point, to move along the curve $\mathrm{ARB}^{\prime}$ where $\mathrm{B}^{\prime}$ in general is a different point from $B$. Another reversal will trace the curve $B^{\prime} \mathrm{R}^{\prime} \mathrm{A}^{\prime}$ where also $\mathrm{A}^{\prime}$ is different from $\mathrm{A}$. If the magnetizing force is reversed many times, the path of the state point eventually becomes a closed curve such as is pictured in Fig. 2. The upper tip of this curve defines a pair of values of $B$ and $H$. If other loops are traced in this manner, but so that each succeeding loop is larger than its predecessor, the locus of the tips of the loops forms the normal curve of ascending reversals, or, as it is sometimes called, the commutation curve. The locus of the lower tips of these same loops is a curve symmetric with this.

\footnotetext{
${ }^{10}$ I have not been able to obtain any iron free from initial polarization and consequently have no data for virgin iron. The experiment cited is not conclusive, as the small residual magnetization detected would tend to produce the same effect attributed to the fact that the iron is in the virgin state.
} 
Instead of starting with a piece of virgin iron, or with a piece of iron which had been thoroughly freed from all previous polarization, we may start with a specimen which has a residual induction represented by the point $\mathrm{P}$ which obviously could lie anywhere on the line $\mathrm{RR}^{\prime}$. Proceeding as before, we get a system of curves analogous to the preceding but with the symmetry lost. The point corresponding to the center of symmetry has been displaced towards $\mathrm{P}$.

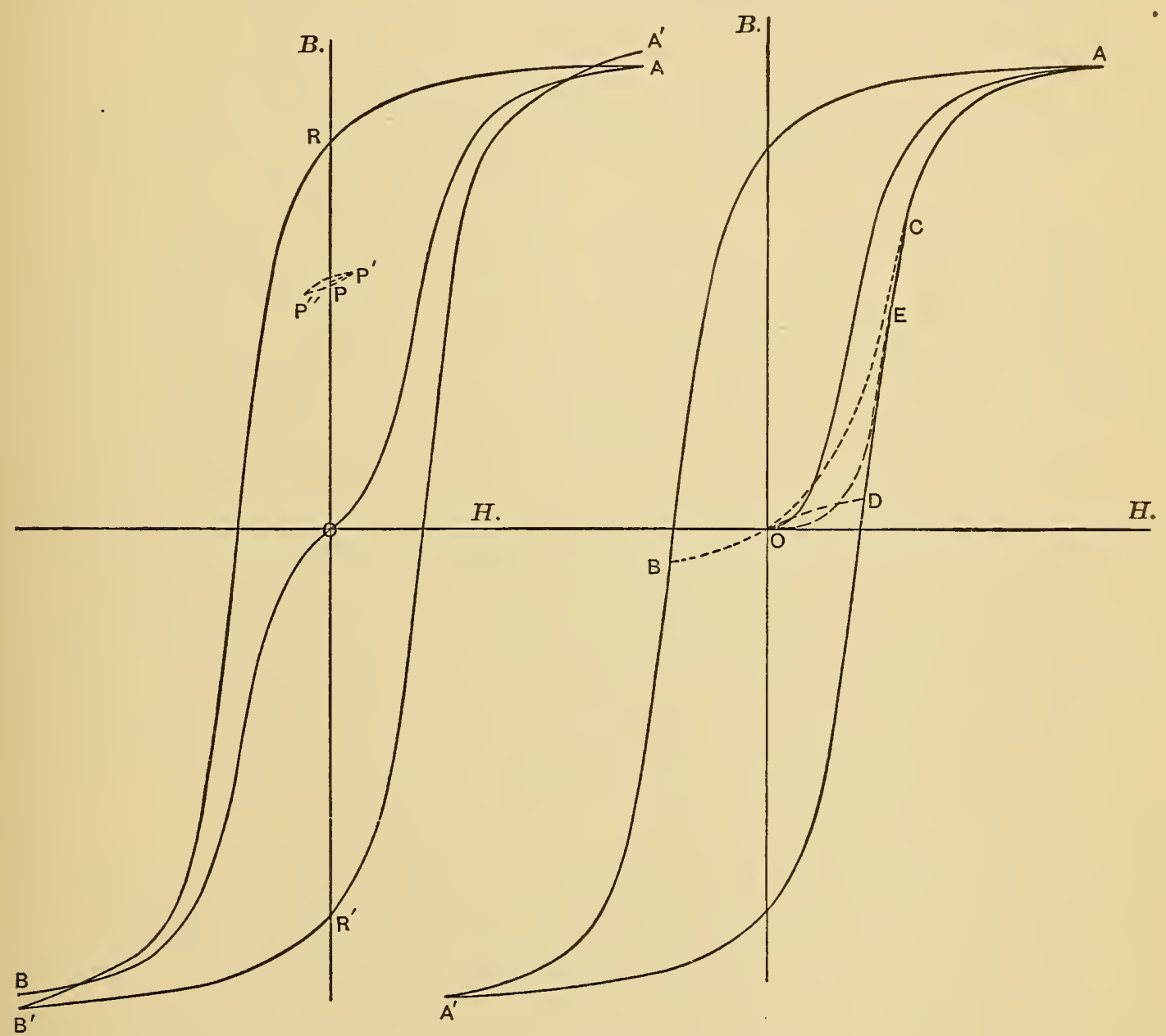

Fig. 1.-Ideal curve to illustrate the definitions of magnetic properties.

Fig. 2.-Ideal curve to illustrate the effect of previous magnetic history on the initial permeability of apparently neutral iron.

This new center may be so far displaced from the origin that on reversals of small values of $H$ the induction does not change sign, but oscillates between two values of the same sign, such as those represented by $\mathrm{P}^{\prime}$ and $\mathrm{P}^{\prime \prime}$. In such a case as this the applied magnetizing force does not determine the absolute induction but only 
the amplitude of the oscillation. Instead of comparing the absolute values of $B$ with $H$, we should rather compare with $H$ the value of this oscillation which is expressible as

$$
\frac{\mathrm{I}}{2}\left(B_{H}-B_{-H}\right)
$$

In order to avoid circumlocution and ambiguity the following definitions seem desirable.

The magnetic induction is one-half the change of magnetic flux per square centimeter observed on the reversal of a given magnetic force, or

$$
\frac{\mathrm{I}}{2}\left(B_{H}-B_{-H}\right)
$$

Permeability is the ratio of this induction to the corresponding magnetizing force, or

$$
\mu=\frac{B}{H}
$$

The differential permeability is the ratio of an infinitesimal change in $B$ to the corresponding change in $H$. Geometrically it is the tangent of the angle which the tangent to the curve makes with the $H$ axis.

The hysteresis loop is the path traced by the state point on a double reversal of a given magnetizing force after sufficient repetition has made the path cyclic.

A normal hysteresis cycle is one which is symmetrical about the origin. The induction and permeability are normal or apparent according as the corresponding hysteresis loops are normal or not. ${ }^{11}$

Iron is in a neutral state when it exerts no external field and yields as readily to a positive magnetizing force as to a negative one.

\section{APPARATUS.}

In these experiments the magnetic circuit usually consisted of two specimens about 50 centimeters long placed side by side with their adjacent ends joined by suitable wrought-iron yokes. The

\footnotetext{
${ }^{11}$ The distinction between "normal" and "apparent" is due to Searle (loc. cit.). Rowland (Physical Papers, p. 44) uses "normal" in the sense of "virgin."
} 
magnetizing coils consisted of two sections, each 40 centimeters long, wound with a single layer of 400 turns of No. 22 double cotton covered magnet wire. The secondary coil was uniformly distributed over the middle portion of the specimen. The shearing correction due to end effects is small and has been allowed for in the results. The reduction to absolute values, as well as other details of manipulation, will be described in a subsequent paper. The nature and dimensions of the specimens used are shown in Table I. For each

\section{TABLE I.}

Showing the physical constants of the specimens used in this work.

\begin{tabular}{|c|c|c|c|c|c|c|}
\hline Specimen & Length & Breadth & $\begin{array}{c}\text { Thick- } \\
\text { ness }\end{array}$ & $\underset{\text { ter }}{\text { Diame- }}$ & $\begin{array}{c}\text { Cross } \\
\text { section }\end{array}$ & $\begin{array}{l}\text { Specific re- } \\
\text { sistance in } \\
\text { micro-ohms }\end{array}$ \\
\hline Transformer iron.. & 51.0 & 1.006 & $* .0355$ & & .0357 & 14.0 \\
\hline Common iron.... & 51.0 & 1.00 & .065 & & .065 & 13.9 \\
\hline Low carbon steel. & 47.1 & & & .578 & .262 & 13.4 \\
\hline High carbon steel.. & 45.8 & & & .578 & .262 & 18.9 \\
\hline
\end{tabular}

* Calculated from mass and density.

kind of iron and steel two specimens were cut from the same rod or sheet, and though cut from adjoining parts show a small difference magnetically.

\section{CRITERION OF PERFECT DEMAGNETIZATION.}

In order to reduce iron to a magnetically neutral state, it must be freed from the effects of previous magnetization. It must not only be freed from all evidences of polarization which would produce an external field and which would be indicated by a suspended magnet or a movable test coil, but also from all internal polarizations which produce no external field. A test coil shows the integrated value of the induction and therefore does not show whether the specimen is in the neutral state. The specimen may be magnetically homogeneous with no external field and yet not be in the neutral state. This appears from Fig. 2. Let the state point be the origin. If the iron is neutral, a small positive force will cause the state point to move along the solid line OA tracing the ascending curve. If, 
however, the iron has been previously carried along the path $\mathrm{OABO}$, the state point is again at the origin, but the iron is so influenced by its recent treatment that a small positive force carries the point along the path OC, which initially is above the normal path OA. Again let it be carried along the path $\mathrm{OABA}^{\prime} \mathrm{DO}$. Once more it is at the origin, but with a tendency to move along the path $\mathrm{OE}$ with increase of $\mathrm{H}$. This latter path is below the normal path. And so on, with various preliminary paths for the state points, we could cause it to leave the origin in an infinite number of directions which would mean an infinite number of initial permeabilities. And yet in each of these cases an external magnet or a movable test coil wonld give no indication of the inherited tendencies of the specimen.

In general, if the origin is made the lower tip of a secondary hysteresis loop, its initial permeability in the ascending curve is less than normal. If, however, the origin is near the middle of the ascending branch of a secondary hysteresis loop, the initial permeability is greater than normal. These facts show that the ordinary criteria for perfect demagnetization are unsatisfactory and indicate that no test is possible which will not modify the neutral state if it should exist.

Before a satisfactory criterion of perfect demagnetization can be determined upon, it is necessary to know something of the nature of the influence a residual induction has on the apparent induction. With this in view, the following experiment was carried out: A specimen was demagnetized as thoroughly as might be and its apparent induction measured. Then the specimen was subjected momentarily to a magnetizing force which would give it a certain residual induction. After the removal of this force the apparent induction for the same force as before was determined. These operations were repeated with successively increasing polarizing forces. The results are shown graphically in Fig. 7. From this curve it is seen that as the polarizing force increases the resultant induction decreases. Applied to Fig. $\mathrm{I}$, this means that the small cyclic loop $\mathrm{P}^{\prime} \mathrm{P} \mathrm{P}^{\prime \prime}$ becomes more nearly parallel to the $H$ axis as $\mathrm{P}$ recedes from this axis. In consequence of this fact, which holds in every case examined, the criterion of perfect demagnetization is that the induction shall be a maximum. 


\section{PREVIOUS METHODS OF DEMAGNETIZATION.}

Many methods have been employed to remove residual polarizations and to reduce the specimen to a magnetically neutral state. The method most generally employed is that of descending reversals in which the demagnetizing force is repeatedly reversed while it is gradually decreased in value. The reversals may be made by hand with an ordinary reversing switch, by a rotating commutator driven either by hand or by power, or by an alternating current. The reduction of current may be made by any form of rheostat. The liquid resistance has found favor in many quarters, chiefly because it gives a continuous variation of current and not a series of steps, as in most types of rheostats.

Ewing ${ }^{12}$ suggests a potential slide, made as follows: A tall glass jar is filled with a dilute solution of zinc sulphate. Three blocks of amalgamated zinc are fitted in the jar-one lying on the bottom, one fixed at the top, and the third hung between them by a cord, which passes over a pulley above to a little winch. The battery is connected to the fixed blocks, and the magnetizing coils to one fixed block and to the movable block. By altering the position of the movable zinc block the electromotive force applied to the magnetizing coils may be varied. Reversals were made by a rotating commutator worked by hand.

Searle ${ }^{13}$ used an alternating current of 90 cycles supplied from the city mains. His resistance consisted of a narrow glass trough containing dilute copper sulphate solution, and furnished with two copper electrodes, one of which was movable. By tilting the trough so that one end was dry the current could be reduced to a very small value.

\section{CURRENT REGULATION.}

In this investigation all the available methods of current control were tried. Several kinds of liquid resistances were used. In some of these the electrodes were inoved apart so as to give a longer path through the liquid. In others the liquid was removed from the containing vessel. This was accomplished in several ways-by tilting the vessel, by siphoning off the liquid to another vessel, and again by allowing the liquid to run out through a stopcock in the

\footnotetext{
${ }^{12}$ Magnetic Induction, etc., p. 44.

${ }^{13}$ Proc. Inst. of Elect. Engrs., 34, p. 6r; I904.
} 
bottom of a tall cylindrical vessel. The latter was the most satisfactory of the liquid type. The ordinary forms of rheostats, with fixed steps, controlled by dial sliding contacts, by plugs, or by links and mercury cups, were tried. Another form used was the Kelvin rheostat, in which the wire is wound from a drum of conducting material to an insulating drum. This gives uniform variation, and is easily controlled, but is laborious. The most satisfactory rheostat used was a cylinder of slate wound with bare wire, having a sliding contact moving parallel to the axis of the cylinder. Several of these resistances of different sizes of wire are connected in series and are highly satisfactory.

Current decrease was also effected by changing the applied electromotive force while keeping the resistance constant. In this case the demagnetizing circuit was connected to two points of an adjustable resistance through which a current was flowing. This method was found to offer no advantage over the preceding, but has some obvious disadvantages.

Early in the investigation it became apparent that the efficiency of demagnetization depended not so much on the total time consumed as on the rate at which the demagnetizing current was reduced. To test this point the demagnetizing current was reduced successively in three different ways. First, so that the rate of increase of resistance was constant; second, so that the rate of decrease of current was approximately constant, and, third, so that the rate of decrease of induction was constant. This last method gave the best results and has been followed in all the later work.

The electromotive force to be used is determined largely by the requirements of the induction measurements to be made after the demagnetization. For these the first requirement is constancy, which is best obtained by a storage battery furnishing no other current. A relatively high voltage is advantageous, because the higher the regulating resistance the easier is the regulation and the lower the time constant of the circuit. These two factors are closely connected with rapidity of the measurements and the accuracy of results. On the other hand, a low voltage means less trouble from arcing at the commutator and less outlay for battery and the extra resistance needed. Twenty volts is an intermediate value, which meets all requirements and has been used in this series of experiments. 
POLARIZATION EFFECT.

It is well at the outset to determine something of the nature of the polarization effects which are to be removed by the process of demagnetization. To this end several specimens of iron were examined after having been exposed to different magnetic treatments. The iron was first demagnetized as well as might be and its apparent induction determined for a series of values of the magnetizing force. Then the iron was subjected to a strong magnetizing force of IoO units (gausses) after which the induction was redetermined. This polarizing force was applied and removed several times, but it was not reversed in this first comparison. The results of this experiment are shown numerically in Tables II, III, IV, and $V$, and

\section{TABLE II.}

To illustrate the effect of the residual polarization due to a force of 100 on the apparent induction in annealed transformer iron.

\begin{tabular}{c|c|c|c|c|c}
\hline $\begin{array}{c}\text { Magnetizing } \\
\text { force }\end{array}$ & $\begin{array}{c}\text { Induction } \\
\text { afterdemagneti- } \\
\text { zation }\end{array}$ & $\begin{array}{c}\text { Apparent } \\
\text { induction when } \\
\text { polarized }\end{array}$ & $\begin{array}{c}\text { Polarization } \\
\text { effect }\end{array}$ & $\begin{array}{c}\text { Per cent } \\
\text { polarization } \\
\text { effect }\end{array}$ & $\mu=\frac{B}{\bar{H}}$ \\
\cline { 1 - 2 } .1 & 68 & 26 & 42 & 62 & 680 \\
.2 & 192 & 67 & 125 & 65 & 960 \\
.3 & 370 & 130 & 240 & 65 & 1260 \\
.4 & 670 & 230 & 440 & 66 & 1670 \\
.5 & 1290 & 480 & 810 & 63 & 2580 \\
.6 & 1680 & 720 & 960 & 57 & 2800 \\
.7 & 2570 & 1380 & 1190 & 46 & 3670 \\
.8 & 3370 & 2510 & 860 & 26 & 4210 \\
.9 & 4300 & 3700 & 600 & 14 & 4780 \\
1.0 & 5130 & 4750 & 380 & 7 & 5130 \\
1.1 & 5710 & 5360 & 350 & 6 & 5170 \\
1.2 & 6730 & 6490 & 240 & 4 & 5230 \\
1.3 & 6880 & 6750 & 130 & 2 & 5290 \\
2.0 & 8880 & 8880 & 0 & 0 & 4440 \\
3.0 & 10750 & 10750 & 0 & 0 & 3580 \\
5.0 & 12750 & 12750 & 0 & 0 & 2550 \\
10.0 & 14620 & 14620 & 0 & 0 & 1460 \\
15.0 & 15280 & 15280 & 0 & 0 & 1020 \\
\hline & & & & & \\
\hline
\end{tabular}

Plotted in Fig. 3. 
TABLE III.

To illustrate the effect of the residual polarization due to a force of 100 on the apparent induction in common sheet iron.

\begin{tabular}{c|c|c|c|c|c}
\hline $\begin{array}{c}\text { Magnetizing } \\
\text { force }\end{array}$ & $\begin{array}{c}\text { Induction } \\
\text { after demagneti- } \\
\text { zation }\end{array}$ & $\begin{array}{c}\text { Apparent } \\
\text { induction when } \\
\text { polarized }\end{array}$ & $\begin{array}{c}\text { Polarization } \\
\text { effect }\end{array}$ & $\begin{array}{c}\text { Per cent } \\
\text { polarization } \\
\text { effect }\end{array}$ & $\mu^{\prime}=\frac{B}{H}$ \\
\hline 1 & 263 & 97 & 166 & 63 & 263 \\
2 & 1314 & 496 & 818 & 62 & 657 \\
3 & 3770 & 3130 & 649 & 17 & 1257 \\
5 & 7890 & 7730 & 160 & 2 & 1580 \\
7 & 10270 & 10130 & 140 & 1 & 1467 \\
10 & 12170 & 12160 & 10 & 0 & 1217 \\
15 & 13610 & 13610 & 0 & 0 & 907 \\
\hline
\end{tabular}

Plotted in Fig. 5 .

TABLE IV.

To illustrate the effect of the residual polarization due to a force of 100 on the apparent induction in low carbon Bessemer steel.

\begin{tabular}{c|c|c|c|c|c}
\hline $\begin{array}{c}\text { Magnetizing } \\
\text { force }\end{array}$ & $\begin{array}{c}\text { Induction } \\
\text { after demagneti- } \\
\text { zation }\end{array}$ & $\begin{array}{c}\text { Apparent } \\
\text { induction when } \\
\text { polarized }\end{array}$ & $\begin{array}{c}\text { Polarization } \\
\text { effect }\end{array}$ & $\begin{array}{c}\text { Percent } \\
\text { polarization } \\
\text { effect }\end{array}$ & \\
\hline 1 & 190 & 90 & 100 & 53 & $\mu=\frac{B}{H}$ \\
2 & 680 & 370 & 310 & 46 & 190 \\
3 & 1930 & 1460 & 470 & 24 & 640 \\
4 & 4150 & 3670 & 480 & 12 & 1040 \\
5 & 6790 & 6300 & 490 & 7 & 1360 \\
7 & 9990 & 9740 & 250 & 3 & 1440 \\
10 & 12470 & 12470 & 0 & 0 & 1250 \\
15 & 14170 & 14170 & 0 & 0 & 940 \\
\hline
\end{tabular}

Plotted in Fig. 4.

graphically in Figs. 3, 5, 4, and 6. From these data and curves it is to be noted that the four specimens of iron show several common characteristics.

(I) The induction after demagnetization is greater than the apparent induction after the intense polarization. The difference between 
TABLE V.

To illustrate the effect of the residual polarization due to a force of 100 on the apparent induction in high carbon crucible steel.

\begin{tabular}{c|c|c|c|c|c}
\hline $\begin{array}{c}\text { Magnetizing } \\
\text { force }\end{array}$ & $\begin{array}{c}\text { Induction } \\
\text { after demagneti- } \\
\text { zation }\end{array}$ & $\begin{array}{c}\text { Apparent } \\
\text { induction when } \\
\text { polarized }\end{array}$ & $\begin{array}{c}\text { Polarization } \\
\text { effect }\end{array}$ & $\begin{array}{c}\text { Per cent } \\
\text { polarization } \\
\text { effect }\end{array}$ & ${ }^{\mu=} \begin{array}{c}B \\
H\end{array}$ \\
\cline { 1 - 2 } 1 & 108 & 54 & 54 & 50 & 108 \\
2 & 249 & 125 & 124 & 50 & 124 \\
3 & 405 & 210 & 195 & 48 & 135 \\
5 & 780 & 440 & 340 & 44 & 156 \\
10 & 2980 & 2600 & 380 & 13 & 298 \\
15 & 6680 & 6610 & 70 & 1 & 445 \\
30 & 10650 & 10650 & 0 & 0 & 335 \\
40 & 11670 & 11670 & 0 & 0 & 292 \\
\hline
\end{tabular}

Plotted in Fig. 6.

these two inductions is a quantity which comes up again and again and may be called the "polarization effect." The polarization effect is a measure of completeness of the previous demagnetization. If the demagnetization is perfect the polarization effect is zero. The first point noted then is that the polarization effect is always positive.

(2) As the magnetizing force under which the apparent induction is measured increases, the polarization effect at first increases, then passes through a maximum, and finally decreases to zero.

(3) The point at which the polarization effect is a maximum is somewhat lower than the point of maximum permeability and near the point where the differential permeability is a maximum.

(4) The point at which the polarization effect vanishes is somewhat above the point of maximum permeability. This vanishing point is a critical point magnetically. We shall therefore denote the corresponding force and induction as "critical demagnetizing force "14 and "critical induction."

(5) While the initial polarization effect initially increases, the normal induction increases so much faster that the percentage polarization effect decreases continuously with increasing magnetizing force.

To test the nature of this polarization effect still further, the

${ }^{14}$ Searle calls this "critical magnetic force." 
annealed transformer iron was demagnetized and subjected momentarily to successively increasing polarizing forces. After each application of the polarizing force a magnetizing force of 0.5 was applied and slowly reversed several hundred times. After the iron had reached a cyclic condition the apparent induction was measured.

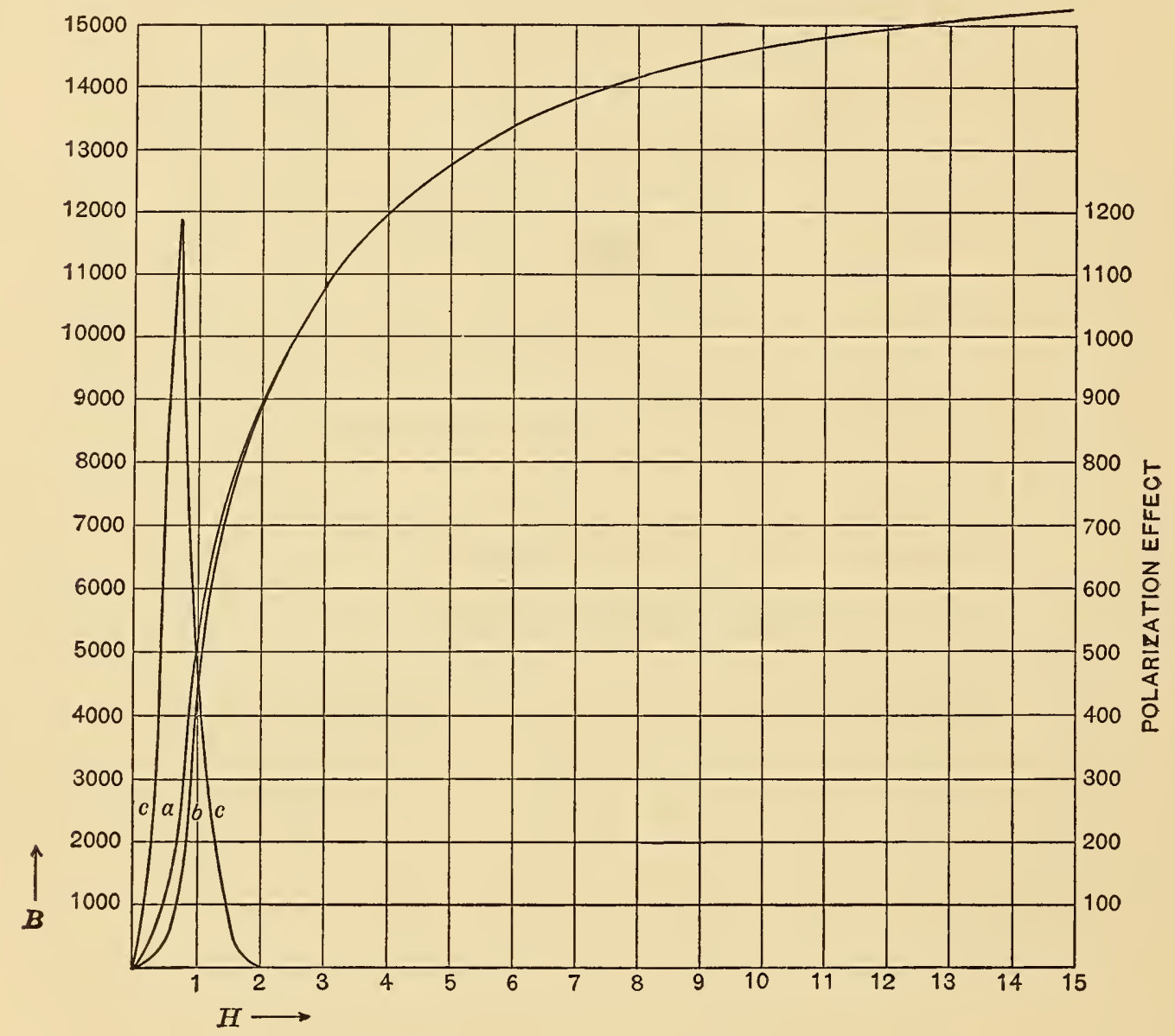

Fig. 3.-Showing characteristics of annealed transformer iron.

(Numerical data in Table II.)

(a) Normal $B-H$ curve.

(b) Apparent $B-H$ curve after intense polarization.

(c) Polarization effect magnified ro-fold relatively to the $B-H$ curves.

The results are shown numerically in Table VI and graphically in Fig. 7. In the curve the apparent induction is plotted against the polarizing force. The same figure may be considered as a curve of polarization effects, for the distance of the curve below the line of normal induction is the polarization effect. It is to be noted that the curve of polarization effect plotted against polarizing force 
TABLE VI.

Showing the influence of various polarizing forces on the apparent induction.

\begin{tabular}{c|c|c|c}
\hline Polarizing force & Apparent induction & Polarization effect & $\begin{array}{c}\text { Polarization effect } \\
\text { polarizing force }\end{array}$ \\
\cline { 2 - 3 } .5 & 1290 & 0 & 0 \\
.6 & 1285 & 5 & 8 \\
.7 & 1260 & 30 & 43 \\
.8 & 1210 & 80 & 100 \\
.9 & 1145 & 145 & 161 \\
1.0 & 1095 & 195 & 195 \\
1.5 & 925 & 365 & 243 \\
2.0 & 820 & 470 & 235 \\
3.0 & 680 & 610 & 203 \\
4.0 & 605 & 685 & 171 \\
5.0 & 555 & 735 & 147 \\
10.0 & 490 & 800 & 80 \\
20.0 & 480 & 810 & 40 \\
\hline
\end{tabular}

Plotted in Fig. 7.

resembles the ordinary $B-H$ curve with initial slope gradual, then passing through a maximum and finally becoming horizontal. However, for polarizing forces between zero and the force under which the apparent induction is measured, the curve is horizontal. This does not mean that polarizing forces less than the magnetizing force studied are without any effect on the iron, but that any such effect is completely wiped out by the repeated reversals of the chosen magnetizing force.

Certain experiments on the effects of imperfect demagnetization seemed to indicate that the data recorded above do not represent the maximum possible polarization effects for the given polarizing forces. To test this point the polarizing force was applied in different ways. Experiment showed that a given force left a greater residual polarization effect if it were reversed several times than if it were simply applied and removed the same number of times. The data of Table VII substantiate this conclusion. The last column of this table shows the difference in polarization effects under these 
two methods of procedure. It is noticeable that these differences are very roughly porportional to the corresponding original polarization effects. This shows that the change due to the reversals of the polarizing force is uniformily distributed, and that the general conclusions as to the nature of the polarization effect hold in this case as well as in the former.

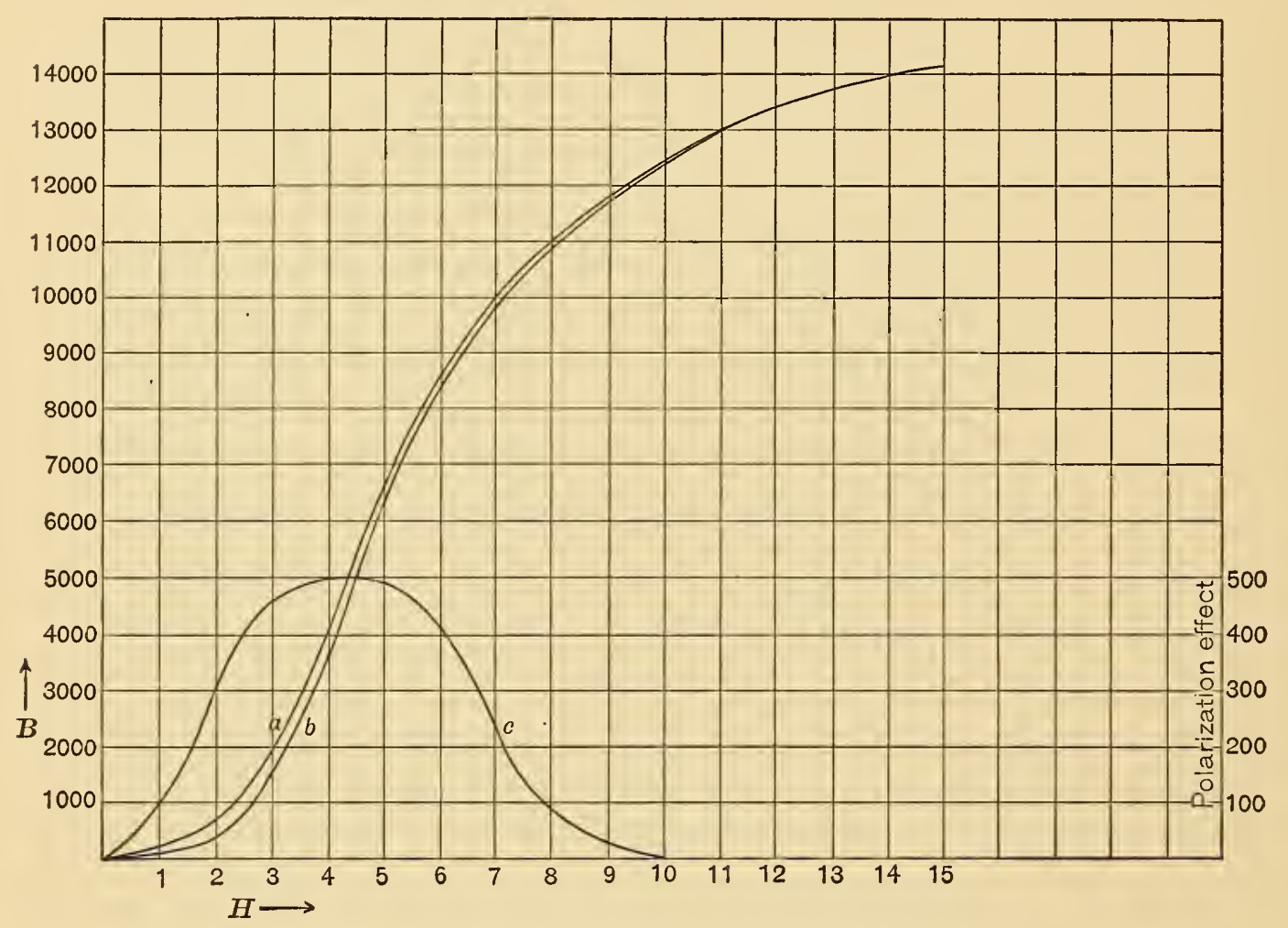

Fig. 4.- Showing characteristics of low carbon steel.

(Numerical data in Table IV.)

(a) Normal $B-H$ curve.

(b) Apparent $B-H$ curve after intense polarization.

(c) Polarization effect magnified Io-fold relatively to the $B-H$ curves.

Since the polarization effect is a continuous function of $H$ and has a maximum at the same value of $H$, though of different magnitude in the two methods of polarizing used, it was assumed that the polarization effect would be a maximum at the same value of $H$ under all conditions, and when it vanished at this force it would have vanished for all other magnetizing forces. This is a rather bold assumption; but it furnishes a good working basis and economizes time, as it allows the characteristics at a single point to typify 
the characteristics of a whole range of points. This assumption is later justified for all the ordinary methods of demagnetization.

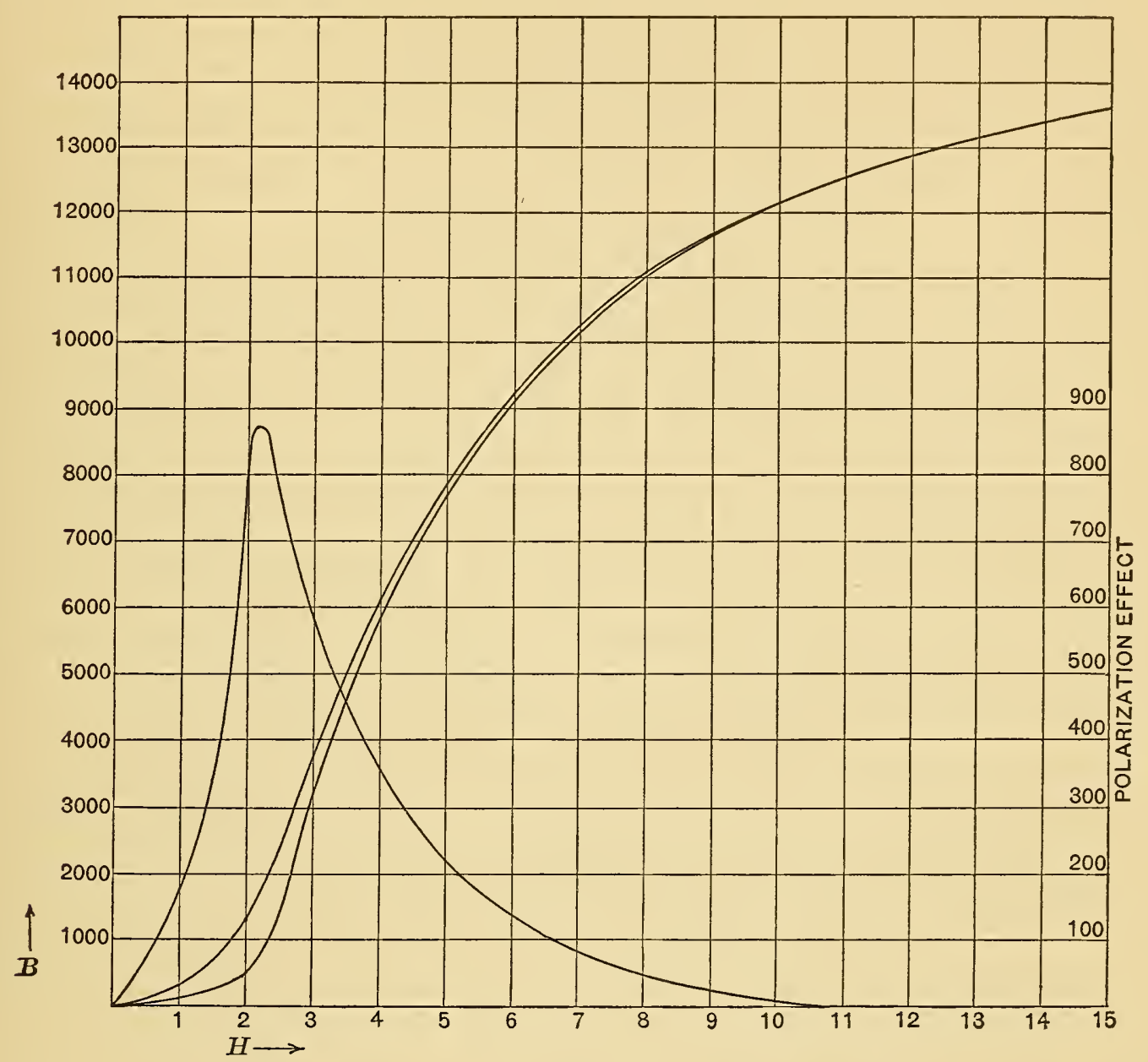

Fig. 5.-Showing characteristics of common sheet iron.

(Numerical data in Table III.)

(a) Normal $B-H$ curve.

(b) Apparent $B-H$ curve after intense polarization.

(c) Polarization effect magnified Io-fold relatively to the $B-H$ curves.

UPPER LIMIT OF THE DEMAGNETIZING FORCE.

It has been assumed in nearly all earlier work ${ }^{15}$ that a necessary condition for perfect demagnetization is that the demagnetizing current must carry the iron from an induction greater than any previous one it has experienced down to a vanishingly small one. The question at once arises as to whether a somewhat smaller range 
might not be equally successful in wiping out the effects of previous polarization.

To determine the maximum value of a necessary yet sufficient demagnetizing force the following experiment was carried out: The specimen was first strongly magnetized by a force of roo to

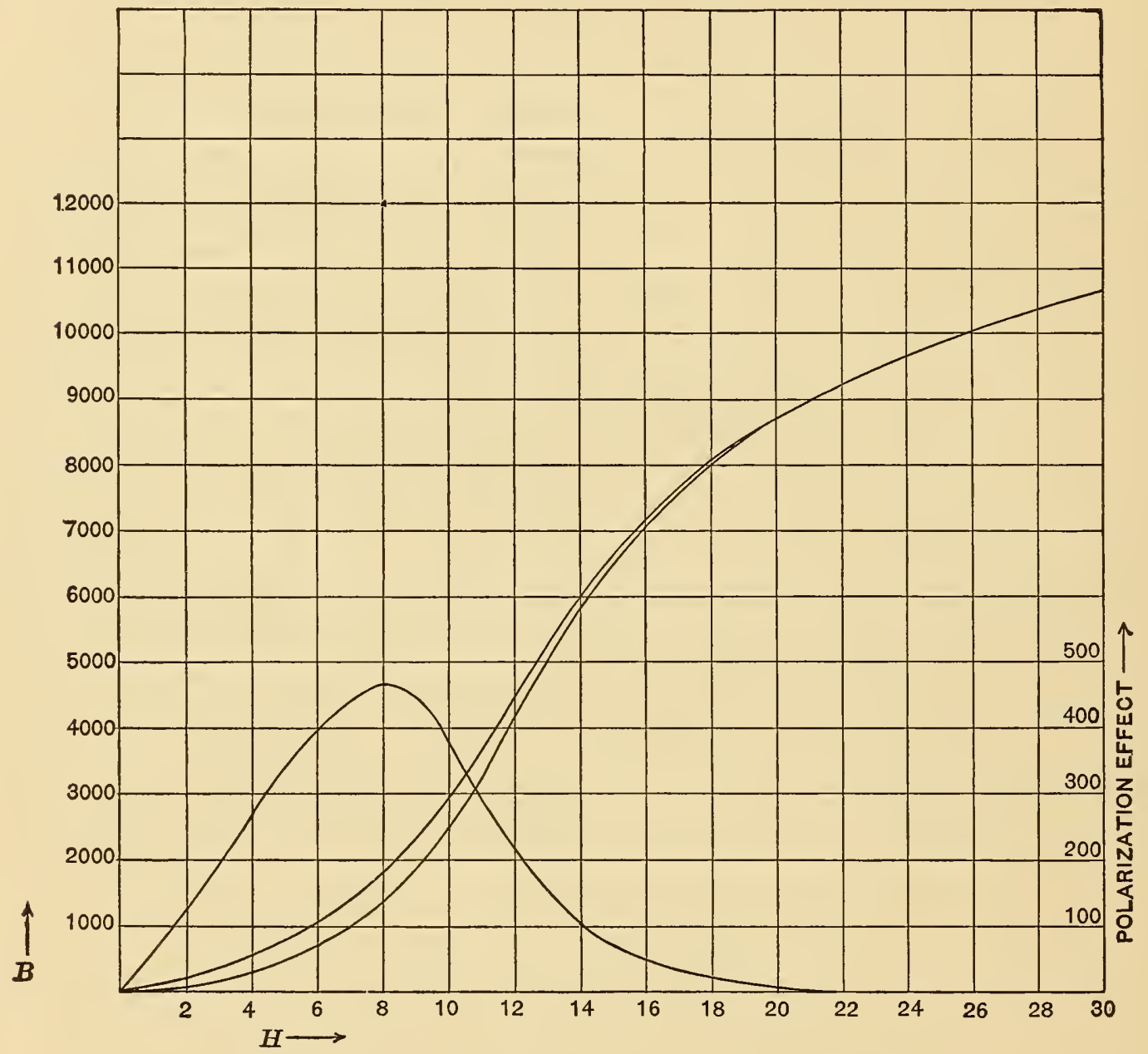

Fig. 6.-Showing characteristics of high carbon steel,

(Numerical data in Table V.)

(a) Normal $B-H$ curve.

(b) Apparent $B-H$ curve after intense polarization.

(c) Polarization effect magnified Io-fold relatively to the $B-H$ curves.

insure a considerable initial polarization. Then it was demagnetized from a certain value of the demagnetizing force down to a vanishingly small force. The cyclic apparent induction was then measured for the value of $H$, at which the previously observed 
polarization effect was a maximum. After this measurement the specimen was again strongly magnetized as before, demagnetized from a second maximum down to the same vanishingly small force, and finally the cyclic apparent induction was measured for the same magnetizing force as before. This process was repeated for a series

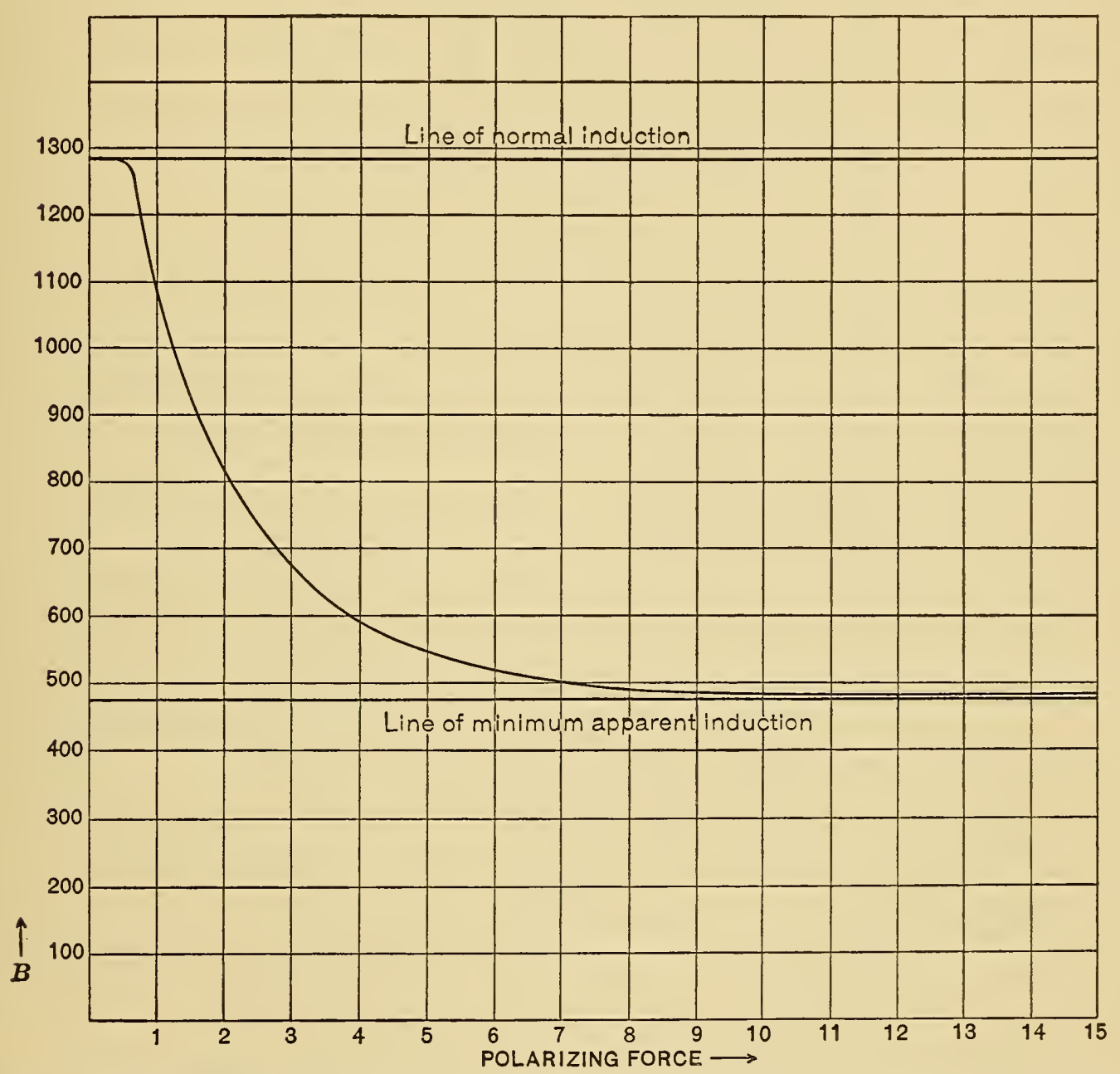

Fig. 7.-Showing the relation between the polarizing force and the apparent induction in annealed transformer iron for $H=0.5$.

(Numerical data in Table VI.)

of values of the maximum demagnetizing force. The results of these experiments are shown graphically in curves marked "curve of upper limits" in Figs. 8, 9, and Io, where the maximum demagnetizing forces are plotted as abscissæ and the apparent inductions as ordinates. From these three curves the following characteristics may be noted: 
(I) For maximum demagnetizing forces greater than the critical demagnetizing force the curve is parallel to the horizontal axis. This indicates that the demagnetization is not improved by carrying the demagnetizing force beyond this critical demagnetizing force.

(2) For maximum demagnetizing forces less than the magnetic force used to determine the apparent induction the curve is again horizontal. This shows that such demagnetization produces no effect that the simple reversals of the magnetizing force used in determining the induction would not accomplish.

TABLE VII.

Showing that the polarizing effect of a field of 100 is greater on reversal than on simple make and break.

\begin{tabular}{c|c|c|c|c}
\hline $\begin{array}{c}\text { Magnetizing } \\
\text { force }\end{array}$ & Normal induction & $\begin{array}{c}\text { Polarization } \\
\text { effect of make } \\
\text { and break }\end{array}$ & $\begin{array}{c}\text { Polarization } \\
\text { effect of } \\
\text { reversals }\end{array}$ & Difference \\
\cline { 2 - 3 } .3 & 370 & 240 & 290 & 50 \\
.4 & 670 & 440 & 520 & 80 \\
.5 & 1290 & 810 & 910 & 100 \\
.6 & 1680 & 960 & 1080 & 120 \\
.7 & 2570 & 1190 & 1310 & 120 \\
.8 & 3370 & 860 & 1050 & 190 \\
.9 & 4300 & 600 & 730 & 130 \\
1.0 & 5130 & 380 & 500 & 120 \\
1.2 & 6730 & 240 & 330 & 90 \\
1.4 & 6950 & 90 & 110 & 20 \\
1.6 & 7610 & 30 & 30 & 0 \\
2.0 & 8880 & 0 & 0 & 0 \\
3.0 & 10750 & 0 & 0 & 0 \\
\hline
\end{tabular}

(3) The two horizontal portions are connected by a smooth curve, indicating that over this range the demagnetization is more or less imperfect but is approaching completeness very rapidly with increase of maximum demagnetizing force.

(4) A comparison of the curves for the soft annealed transformer iron, the moderately hard low carbon steel, and the hard high carbon steel shows that the steepness of this sloping portion of the curve and the sharpness of the bends at its upper and lower extremities decreases as the hardness of the iron increases. 
TABLE VIII.

Showing the apparent induction in annealed transformer iron as influenced by the upper limit of the demagnetizing force.

\begin{tabular}{|c|c|c|c|c|c|}
\hline $\begin{array}{l}\text { Limits of demag- } \\
\text { netizing force }\end{array}$ & 3 (or more) -.2 & $2-.2$ & $\mathrm{I}-.2$ & $.5-.2$ & \multirow{3}{*}{ No demagnet- } \\
\hline Time interval & 92.4 & 72.4 & 99 & $9 r .8$ & \\
\hline \multirow[t]{2}{*}{ Number of cycles } & $\mathrm{I}_{45}$ & 107 & I54 & I35 & \\
\hline & $B$ & $B$ & $B$ & $B$ & $B$ \\
\hline$H=.3$ & 370 & 360 & 320 & 220 & 130 \\
\hline .4 & 670 & 670 & 630 & 360 & 230 \\
\hline .5 & 1290 & 1290 & 1210 & 740 & 480 \\
\hline .6 & 1680 & 1680 & 1570 & 770 & 720 \\
\hline .7 & 2570 & 2570 & 2340 & 1530 & 1380 \\
\hline .8 & 3370 & 3370 & 2990 & 2460 & 2510 \\
\hline .9 & 4300 & 4300 & 3780 & 3580 & 3700 \\
\hline 1.0 & 5130 & 5130 & 4620 & 4650 & 4750 \\
\hline 1.2 & 6730 & 6730 & 6370 & 6370 & 6490 \\
\hline 1.4 & 6950 & 6950 & 6720 & 6710 & 6860 \\
\hline 1.6 & 7610 & 7610 & 7390 & 7390 & 7580 \\
\hline 2.0 & 8880 & 8880 & 8730 & 8730 & 8880 \\
\hline 3.0 & 10750 & 10750 & 10750 & 10750 & 10750 \\
\hline
\end{tabular}

TABLE IX.

Showing polarization effects (calculated from Table VIII).

\begin{tabular}{c|r|r|r|r|r}
\hline $\begin{array}{c}\text { Limits of demag- } \\
\text { netizing force }\end{array}$ & $3-.2$ & $2-.2$ & I-.2 & $.5-.2$ & $\begin{array}{c}\text { Nodemagnet- } \\
\text { ization }\end{array}$ \\
\hline .3 & 0 & 10 & 50 & 150 & 240 \\
.4 & 0 & 0 & 40 & 310 & 440 \\
.5 & 0 & 0 & 80 & 550 & 810 \\
.6 & 0 & 0 & 110 & 910 & 960 \\
.7 & 0 & 0 & 230 & 1040 & 1190 \\
.8 & 0 & 0 & 380 & 910 & 860 \\
.9 & 0 & 0 & 520 & 720 & 600 \\
1.0 & 0 & 0 & 510 & 480 & 380 \\
1.2 & 0 & 0 & 360 & 360 & 240 \\
1.4 & 0 & 0 & 230 & 240 & 90 \\
1.6 & 0 & 0 & 220 & 220 & 30 \\
2.0 & 0 & 0 & 150 & 150 & 0 \\
3.0 & 0 & 0 & 0 & 0 & 0 \\
\hline
\end{tabular}


TABLE X.

Showing the apparent induction in common sheet iron as influenced by the upper limit of the demagnetizing force.

\begin{tabular}{|c|c|c|c|c|}
\hline $\begin{array}{l}\text { Limits of demag- } \\
\text { netizing force }\end{array}$ & IO-I & $7-1$ & $5-I$ & \multirow{3}{*}{$\begin{array}{c}\text { No demagneti- } \\
\text { zation }\end{array}$} \\
\hline Time interval & 54 & 42 & 32 & \\
\hline Number of cycles & 84 & $\sigma_{4}$ & 48 & \\
\hline$H$ & $B$ & $B$ & $B$ & $B$ \\
\hline 1 & 263 & 255 & 255 & 97 \\
\hline 2 & 1314 & 1304 & 1304 & 496 \\
\hline 3 & 3770 & 3750 & 3740 & 3130 \\
\hline 5 & 7890 & 7810 & 7700 & 7730 \\
\hline 7 & 10270 & 10200 & 10170 & 10130 \\
\hline 10 & 12170 & 12170 & 12160 & 12160 \\
\hline 15 & 13610 & 13610 & 13610 & 13610 \\
\hline
\end{tabular}

TABLE XI.

Showing polarization effects (calculated from Table X).

\begin{tabular}{c|r|r|r|r}
\hline $\begin{array}{c}\text { Limits of demag- } \\
\text { netizing force }\end{array}$ & Io-I & $7-\mathbf{r}$ & $5-\mathbf{r}$ & $\begin{array}{c}\text { No demagneti- } \\
\text { zation }\end{array}$ \\
\hline$H=1$ & 0 & 8 & 8 & 166 \\
2 & 0 & 10 & 10 & 818 \\
3 & 0 & 20 & 30 & 640 \\
5 & 0 & 80 & 190 & 160 \\
7 & 0 & 70 & 100 & 140 \\
10 & 0 & 0 & 10 & 10 \\
15 & 0 & 0 & 0 & 0 \\
\hline
\end{tabular}


TABLE XII.

Showing the apparent induction in low carbon steel as influenced by the upper limit of the demagnetizing force.

\begin{tabular}{|c|c|c|c|c|}
\hline $\begin{array}{l}\text { Limits of demag- } \\
\text { netizing force }\end{array}$ & $15-.2$ & $10-.2$ & $5-.2$ & \multirow{3}{*}{$\begin{array}{c}\text { No demagneti- } \\
\text { zation }\end{array}$} \\
\hline Time interval & 70 & 70 & 49 & \\
\hline \multirow[t]{2}{*}{ Number of cycles } & 100 & 100 & 70 & \\
\hline & $B$ & $B$ & $B$ & $B$ \\
\hline$H=1$ & 190 & 190 & 183 & 90 \\
\hline 2 & 680 & 675 & 667 & 370 \\
\hline 3 & 1930 & 1920 & 1897 & 1460 \\
\hline 4 & 4150 & 4130 & 3990 & 3470 \\
\hline 5 & 6790 & 6745 & 6590 & 6300 \\
\hline 6 & 9140 & 9100 & 9000 & 8670 \\
\hline 7 & 9990 & 9960 & 9920 & 9740 \\
\hline 8 & 11070 & 11060 & 11040 & 10950 \\
\hline 9 & 11880 & 11870 & 11870 & 11820 \\
\hline 10 & 12470 & 12460 & 12470 & 12460 \\
\hline 15 & 14170 & 14170 & 14170 & 14170 \\
\hline
\end{tabular}

TABLE XIII.

Showing polarization effects (calculated from Table XII).

\begin{tabular}{c|r|r|r|r}
\hline $\begin{array}{c}\text { Limits of demag } \\
\text { netizing force }\end{array}$ & $15-.2$ & 10-.2 & $5-.2$ & $\begin{array}{c}\text { No demagneti- } \\
\text { zation }\end{array}$ \\
\hline 1 & 0 & 0 & 7 & 100 \\
2 & 0 & 5 & 13 & 310 \\
3 & 0 & 10 & 33 & 470 \\
4 & 0 & 20 & 160 & 480 \\
5 & 0 & 45 & 200 & 490 \\
6 & 0 & 40 & 140 & 370 \\
7 & 0 & 30 & 70 & 250 \\
8 & 0 & 10 & 30 & 120 \\
9 & 0 & 10 & 10 & 60 \\
10 & 0 & 10 & 0 & 10 \\
15 & 0 & 0 & 0 & 0 \\
\hline
\end{tabular}


The preceding applies to a single value of the magnetizing force. To show that this is typical, and to get further light on the nature of the polarization effect under different degrees of completeness in the demagnetization, the full range of points was taken for a few different sets of magnetizing limits. The data for the apparent inductions after various demagnetizations in which the upper limit

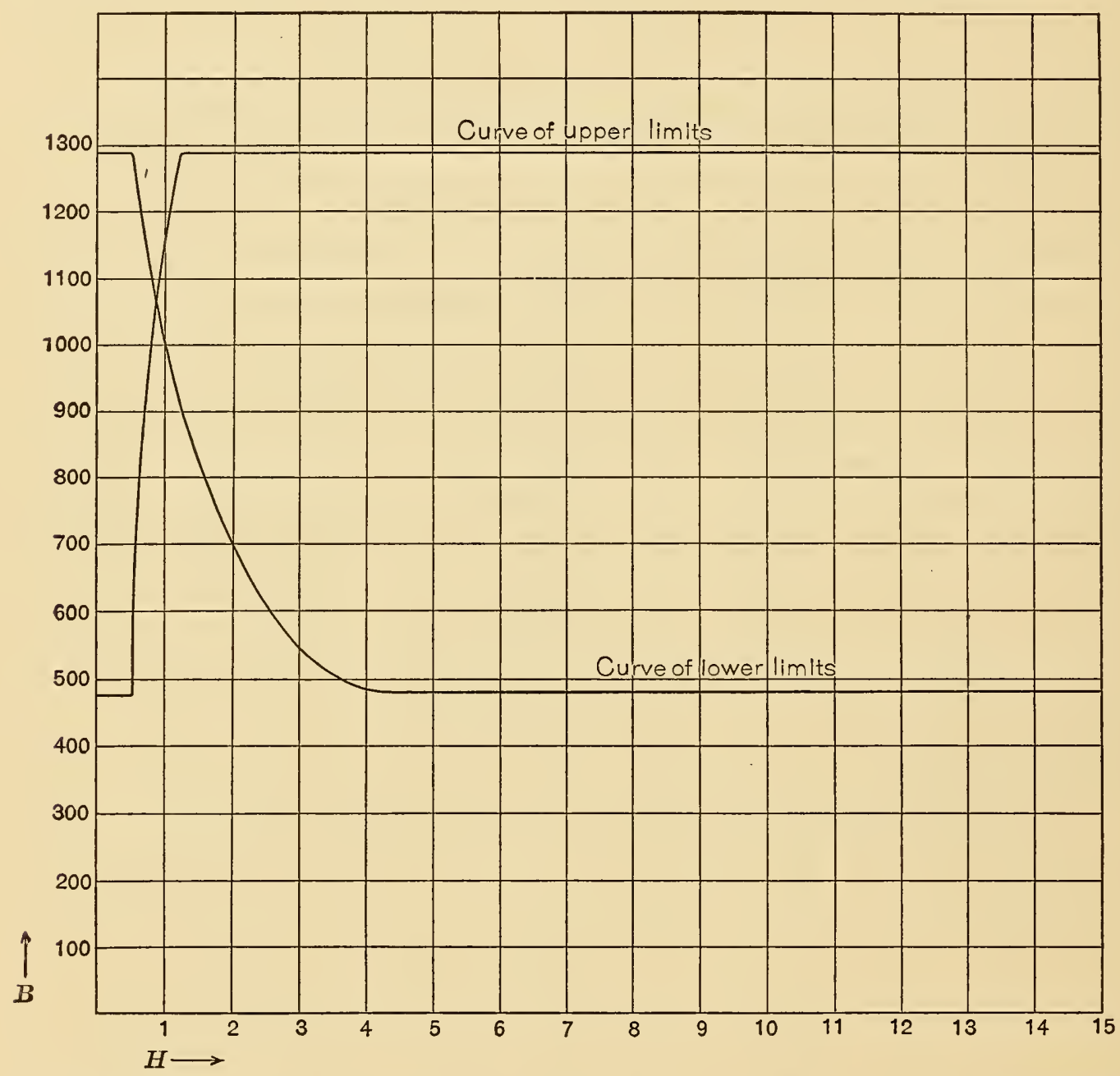

Fig. 8.- Showing the influence of the upper and lower limits of the demagnetizing force on the apparent induction of annealed transformer iron for $H=0.5$.

alone was altered are given in Tables VIII, X, and XII. The corresponding data for the polarization effects are more instructive and are given in Tables IX, XI, and XIII. From these six tables the following conclusions may be drawn:

(I) The demagnetization is complete throughout the whole range if the upper limit is at least as great as the critical demagnetizing force. 
(2) If the maximum demagnetizing force is less than the critical demagnetizing force, the demagnetization is in general incomplete, and the incompleteness extends over practically the whole region from the lowest values of the magnetizing force up to the critical value. This region may be called the domain of the polarization effect.

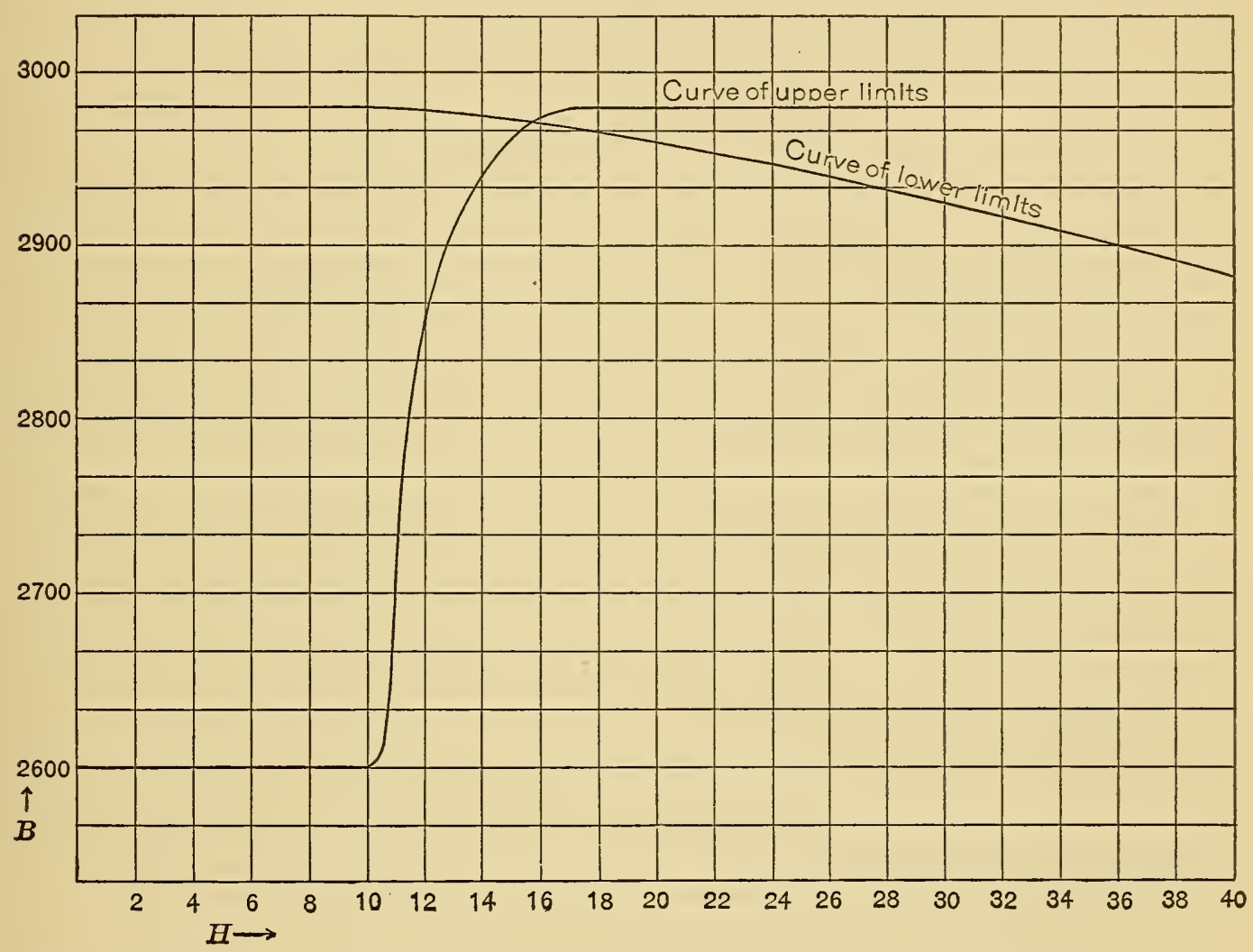

Fig. 9.-Showing the influence of the upper and lower limits of the demagnetizing force on the apparent induction of high carbon steel for $H=I O$.

(3) The polarization effect increases as the maximum demagnetizing force decreases, but preserves its general characteristics as described above.

(4) In certain cases the polarization effect is greater after a feeble demagnetization than without any demagnetization. ${ }^{16}$ Tables IX and $\mathrm{XI}$ for the transformer iron and the common sheet iron, resepctively, show this very clearly. This phenomenon occurs at or below the point of maximum permeability. It was this peculiar increase of polarization that suggested the comparison of polarization effects 
after repeated simple make and break, with those after reversals. A comparison with those results in Table VII will show that the increased polarization effect is still less than the maximum observed on reversal.

Some further observations on the effect of varying the upper limit of the demagnetizing force will be made under the discussion of the influence of frequency of an alternating current demagnetization on the polarization effect.

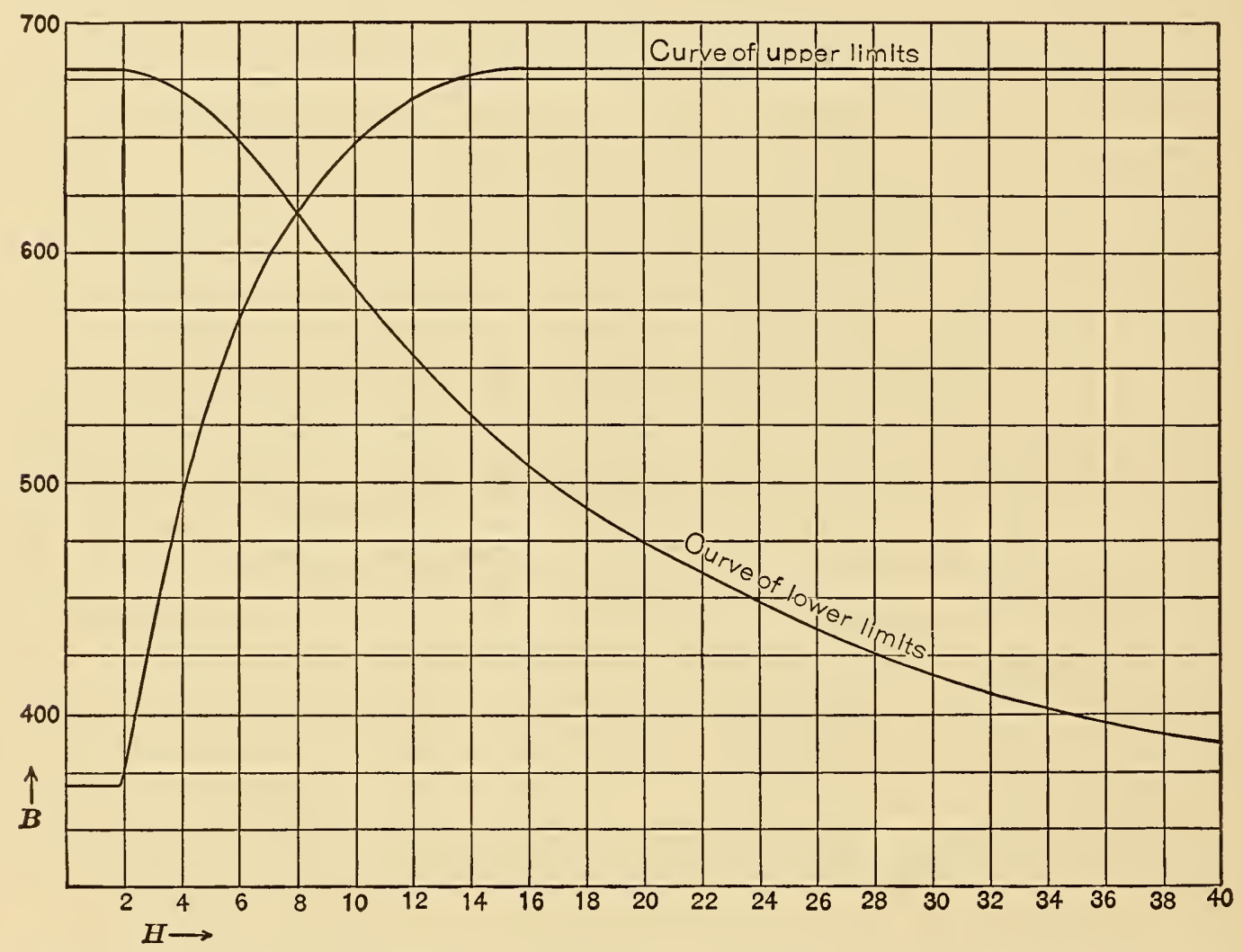

Fig. 10.-Showing the influence of the upper and lower limits of the demagnetizing force on the apparent induction of low carbon steel for $H=2$.

LOWER LIMITS OF THE DEMAGNETIZING FORCE.

Having settled upon a proper value for the upper limit of the demagnetizing force, it now remains to determine the necessary and sufficient final minimum value of this force. For this purpose an experiment similar to the preceding was carried out. The specimen was polarized initially as before. The demagnetization was carried from a point well above the critical demagnetizing force down to a certain minimum value. Finally the cyclic apparent induction was 
measured for the same force as in the preceding experiment. These operations were repeated, modifying only the final minimum value of the demagnetizing force. The results of this experiment are shown graphically in the curves marked "curve of lower limits" in Figs. 8, 9, and Io. The minimum value of the demagnetizing force is plotted as abscissa and the corresponding cyclic apparent induction as ordinate. Both coordinates are plotted to the same scale as in the curve of upper limits. From these curves the following conclusions may be drawn:

\section{TABLE XIV.}

Showing the apparent induction of annealed transformer iron as influenced by the lower limit of the demagnetizing force.

\begin{tabular}{|c|c|c|c|c|c|}
\hline $\begin{array}{l}\text { Limits of demag- } \\
\text { netizing force }\end{array}$ & $15-.32$ & $15-.5$ & $15-1.15$ & $15-2.6$ & \multirow{3}{*}{$\begin{array}{c}\text { No demagnet } \\
\text { ization }\end{array}$} \\
\hline Time interval & 95.8 & 97.8 & 66 & 60 & \\
\hline Number of cycles & г60 & 155 & I04 & 96 & \\
\hline$H$ & $B$ & $B$ & $B$ & $B$ & $B$ \\
\hline .3 & 370 & 352 & 250 & 160 & 130 \\
\hline .4 & 670 & 660 & 450 & 340 & 230 \\
\hline .5 & 1290 & 1290 & 990 & 645 & 480 \\
\hline .6 & 1680 & 1680 & 1470 & 1000 & 720 \\
\hline .7 & 2570 & 2570 & 2420 & 1800 & 1380 \\
\hline .8 & 3370 & 3370 & 3180 & 2700 & 2510 \\
\hline .9 & 4300 & 4300 & 4270 & 3870 & 3700 \\
\hline 1.0 & 5130 & 5130 & 5110 & 5030 & 4750 \\
\hline 1.2 & 6730 & 6730 & 6730 & 6690 & 6490 \\
\hline 1.4 & 6950 & 6950 & 6950 & 6950 & 6860 \\
\hline 1.6 & 7610 & 7610 & 7610 & 7610 & 7580 \\
\hline 2.0 & 8880 & 8880 & 8880 & 8880 & 8880 \\
\hline 3.0 & 10750 & 10750 & 10750 & 10750 & 10750 \\
\hline
\end{tabular}

(I) For values of lower limit of the demagnetizing force less than the magnetizing force which produces the apparent induction, the curve is a horizontal line. This indicates that the demagnetization is not improved by carrying the demagnetizing force below the lowest magnetizing force to be studied. 
(2) For values of the lower limit considerably greater than the critical demagnetizing force the curve is a horizontal straight line and indicates that the demagnetizing force does not modify the previously existing polarization effect; at least it does not modify that portion of it which repeated reversals of the given magnetizing force do not eliminate.

(3) Between the two horizontal portions is a continuous sloping curve, which indicates a partial demagnetization which increases in completeness very rapidly as the lower limit of the demagnetizing force decreases.

\section{TABLE XV.}

Showing the apparent induction of common sheet iron as influenced by the lower limit of the demagnetizing force.

\begin{tabular}{|c|c|c|c|c|c|c|}
\hline $\begin{array}{l}\text { Limits of demag- } \\
\text { netizing force }\end{array}$ & $15-I$ & $15^{-2}$ & I5-3 & $15-5$ & $15-7$ & \\
\hline Time interval & 38 & 37 & $3 \mathbf{I}$ & 22 & 17 & $\begin{array}{l}\text { No demag- } \\
\text { netization }\end{array}$ \\
\hline Number of cycles & $5^{6}$ & 52 & 48 & 32 & 26 & \\
\hline$H$ & $B$ & $B$ & $B$ & $B$ & $B$ & $B$ \\
\hline 1 & 263 & 255 & 197 & 151 & 120 & 97 \\
\hline 2 & 1314 & 1314 & 1224 & 890 & 820 & 496 \\
\hline 3 & 3770 & 3770 & 3770 & 3350 & 3220 & 3130 \\
\hline 5 & 7890 & 7890 & 7890 & 7890 & 7860 & 7730 \\
\hline 7 & 10270 & 10270 & 10270 & 10270 & 10270 & 10130 \\
\hline 10 & 12170 & 12170 & 12170 & 12170 & 12170 & 12160 \\
\hline 15 & 13610 & 13610 & 13610 & 13610 & 13610 & 13610 \\
\hline
\end{tabular}

(4) A comparison of the curves for three grades of iron and steel shows that the steepness of the curved portion and the sharpness of the bends at the upper and lower extremities decrease as we pass from the softer to the harder material. The lower horizontal portion occurs at extremely high values in the hard material. (Figs. 9 and ro.)

To justify the above conclusions drawn from measurements made at a single value of the magnetizing force, and to investigate further the nature of the polarization effect several complete apparent induction curves were obtained under different details of demagnetization. 
These complete data are given in Tables XIV, XV, and XVI. From these data the preceding conclusions are justified, and the following generalization appears: If the demagnetization is carried from the critical demagnetizing force down to a certain point, the demagnetization is complete for all values above the final demagnetizing force. For magnetizing forces below this final value of demagnetization the demagnetization is incomplete, and the incompleteness is greater the greater the interval between the final demagnetizing force and the magnetizing force used to produce the induction desired.

\section{TABLE XVI.}

Showing the apparent induction of low carbon steel as influenced by the lower limit of the demagnetizing force.

\begin{tabular}{|c|c|c|c|c|c|}
\hline $\begin{array}{l}\text { Limits of demag- } \\
\text { netizing force }\end{array}$ & $15-.2$ & $15-2.5$ & $15-3$ & $15-5$ & \\
\hline Time interval & 75 & 73 & I67 & ${ }^{1}{ }^{6}$ & ization \\
\hline Number of cycles & 83 & 80 & 200 & 180 & \\
\hline$H$ & $B$ & $B$ & $B$ & $B$ & $B$ \\
\hline 1 & 190 & 185 & 175 & 152 & 90 \\
\hline 2 & 680 & 680 & 668 & 566 & 370 \\
\hline 3 & 1930 & 1930 & 1930 & 1795 & 1460 \\
\hline 4 & 4150 & 4150 & 4150 & 4150 & 3470 \\
\hline 5 & 6790 & 6790 & 6790 & 6790 & 6300 \\
\hline 6 & 9140 & 9140 & 9140 & 9140 & 8670 \\
\hline 7 & 9990 & 9990 & 9990 & 9990 & 9740 \\
\hline 8 & 11070 & 11070 & 11070 & 11070 & 10950 \\
\hline 9 & 11880 & 11880 & 11880 & 11880 & 11820 \\
\hline 10 & 12470 & 12470 & 12470 & 12470 & 12460 \\
\hline 15 & 14170 & 14170 & 14170 & 14170 & 14170 \\
\hline
\end{tabular}

EDDY CURRENTS-THEORY.

If we use an alternating current in demagnetizing, we must consider the shielding effect which the eddy currents exert on the interior of the specimen. The magnetizing force at any point is the resultant of the force due to the current in the wire and the force due to the eddy currents in the specimen. The calculation of this 
force presents great difficulties unless certain simplifying assumptions are made. Heaviside ${ }^{17}$ in a paper entitled "The Induction of Currents in Cores," gives a solution for the special case of a round rod of constant permeability magnetized by a simple harmonic force. In this case the force at any point of the specimen is a function of

$\mu=$ the permeability.

$\rho=$ the specific resistance.

$N=$ the frequency.

$r=$ the distance of the point from the axis.

If we let $x=\frac{8 \pi^{2} \mu N}{\rho}$ the resultant magnetic force at any point is

$$
H=A M+B N
$$

where $A$ and $B$ are constants, and

$$
\begin{aligned}
M & =\frac{I}{2}\left\{J_{0}(r \sqrt{-i x})+J_{o}(r \sqrt{i x})\right\} \\
& =I-\frac{x^{2} r^{4}}{2^{2} \cdot 4^{2}}+\frac{x^{4} r^{8}}{2^{2} \cdot 4^{2} \cdot 6^{2} \cdot 8^{2}}-\ldots \ldots \\
N & =\frac{I}{2 i}\left\{J_{o}(r \sqrt{-i x})-J_{o}(r \sqrt{i x})\right\} \\
& =\frac{x r^{2}}{2^{2}}-\frac{x^{3} r^{6}}{2^{2} \cdot 4^{2} \cdot 6^{2}}+\frac{x^{5} r^{10}}{2^{2} \cdot 4^{2} \cdot 6^{2} \cdot 8^{2} \cdot \mathrm{IO}^{2}}-\ldots \ldots
\end{aligned}
$$

The maximum value of $H$ at any point in the core is proportional to

$$
\sqrt{M^{2}+N^{2}}
$$

By squaring the expressions for $M$ and $N$, and adding, we have

$$
\begin{aligned}
M^{2}+N^{2} & =J_{0}(r \sqrt{-i x}) J_{0}(r \sqrt{i x}) \\
& =\mathrm{I}+\frac{2 y}{2^{2} \cdot 4^{2}}\left(\mathrm{I}+\frac{3 y}{6^{2} \cdot 8^{2}}\left(\mathrm{I}+\frac{3 \frac{1}{3} y}{\mathrm{IO} \cdot \mathrm{I} 2^{2}}\left(\mathrm{I}+\frac{3 \frac{1}{2} y}{\mathrm{I} 4^{2} \cdot \mathrm{I} 6^{2}}\left(\mathrm{I}+\frac{3 \frac{3}{5} y}{\mathrm{I} 8^{2} \cdot 20^{2}}(\mathrm{I}+\ldots\right.\right.\right.\right.
\end{aligned}
$$

where $y=x^{2} r^{4}$.

Since every term of the series is positive, the amplitude increases as we pass from the axis outward. To get some idea of the relative 
magnitude of the amplitudes at various distances from the axis, I have calculated values of $\sqrt{M^{2}+N^{2}}$ for different values of $y$. These calculated values are shown graphically in Fig. 25, where $\sqrt{M^{2}+N^{2}}$ is plotted as abscissa and $y$ as ordinate. $\sqrt{M^{2}+N^{2}}$ is the ratio of the amplitude for a given value of $y$ to the amplitude at the center where $y$ is zero.

Putting

$$
\begin{aligned}
\mu & =\text { I000 } \\
\rho & =\text { I000o c. g. s. units (= Io micro-ohms) } \\
N & =60
\end{aligned}
$$

we have

$$
\begin{aligned}
y & =x^{2} r^{4} \\
& =\left[\frac{8 \pi^{2} \mu N}{\rho}\right]^{2} r^{4} \\
y & =224000 r^{4}
\end{aligned}
$$

The last equation is plotted on the left half of Fig. 25 in connection with the curve of amplitudes; $y$ is plotted upward on the same axis for both curves. The distance from the center $r$ is plotted to the left. Curves are drawn also for $\mu=500$ and $\mu=2000$. From this figure the relative amplitudes at any distance from the axis may be obtained, subject of course to the conditions stated above. Apply this to a rod of the dimensions of the low carbon rod already used. If $\mu=500$, a point on the surface, $r=0.29 \mathrm{~cm}$, corresponds to the point $\mathrm{P}$ on the $(y, r)$ curve and $\mathrm{Q}$ on the $\left(\sqrt{M^{2}+N^{2}}, y\right)$ curve, so that at the surface of the rod the maximum induction is 4.4 times its value at the axis. For $\mu=$ rooo the maximum induction at the boundary is 14 times the value at the axis. The induction has half the boundary value at $r=0.235 \mathrm{~cm}$, showing that the resultant force, and consequently the induction, is much greater in the outer layers of the rod. The flatness of the $(y, r)$ curve for small values of $r$ shows that the force and flux are nearly uniform near the axis of the rod. This variation of the resultant magnetic force throughout the cross section of the rod increases with increase 
of radius, frequency, conductivity, and permeability, and leads us to expect incomplete demagnetization by alternating currents unless relatively large currents are used. The following experiments show that the observed facts are in harmony with the theory.

\section{FREQUENCY OF THE DEMAGNETIZING CURRENT.}

In determining the effects on the resultant apparent induction of the rate of reversal of the demagnetizing current, various samples of iron were tested using (a) alternating current of a wide range of frequencies and $(b)$ direct current reversed by a rotating commutator or by a hand commutator. A special harmonic generator set capable of yielding individually any of the first eight odd harmonics to a fundamental frequency of 60 cycles per second, was used to produce frequencies of 900, 780, 660, 540, 420, 300, I80, and 6o. Separate machines were used to generate frequencies of $\mathrm{I} 20,90$, and 60 cycles per second. By reducing the speed of the 60 cycle generator frequencies of 30 and 20 cycles per second were obtained. A motordriven rotating commutator reversed a direct current so as to furnish frequencies ranging from ${ }_{5} 5$ cycles to $\mathrm{I}$ cycle per second. An ordinary reversing switch, worked by hand, gave frequencies of from 5 cycles down to one-half cycle per second. By these means a wide range of frequencies extending from 900 cycles per second down to one-half cycle per second was obtained. As in the earlier work the specimens used were annealed transformer iron, mild low carbon steel, and hard high carbon tool steel.

The transformer iron was investigated under three conditions. First, the apparent induction was measured with the magnetic circuit composed of the two specimens placed as close as the nnagnetizing coils would allow and the air gaps between the adjacent ends; that is, the specimens were not united by yokes. In the second arrangement the ends of the specimens were joined by $\mathrm{U}$-shaped pieces of iron of the same material and cross section. This was an attempt to have a homogeneous magnetic circuit. In the last arrangement the specimens were connected by massive soft-iron yokes such as might ordinarily be used in the double-yoke method. The data for this experimental work on the transformer iron are shown graphically in Fig. II, where curves I, II, and III show the results obtained without yokes, with the equisectional yokes, 
TABLE XVII.

Showing how the apparent induction at a given magnetizing force decreases with the increase in the frequency of the demagnetizing current.

\begin{tabular}{c|c|c|c|c|c|c}
\hline & $\begin{array}{c}\text { High car- } \\
\text { bon steel }\end{array}$ & $\begin{array}{c}\text { Low carbon } \\
\text { steel }\end{array}$ & $\begin{array}{c}\text { Soft iron with } \\
\text { massive yokes }\end{array}$ & $\begin{array}{c}\text { Soft iron with } \\
\text { yokes of same } \\
\text { cross section }\end{array}$ & $\begin{array}{c}\text { Soft iron with- } \\
\text { out yokes }\end{array}$ & Frequency \\
\cline { 1 - 2 }$B_{120}$ & 7.0 & 2.0 & 0.5 & 0.5 & 0.5 & \\
$B_{90}$ & 1332 & 617 & 1134 & 1176 & 1181 & 120 \\
$B_{60}$ & 1336 & 621 & 1178 & 1221 & 1229 & 90 \\
$B_{30}$ & 1338 & 630 & 1207 & 1240 & 1246 & 60 \\
$B_{15}$ & 1360 & 647 & 1243 & 1265 & 1270 & 30 \\
$B_{10}$ & 1365 & 663 & 1266 & 1278 & 1280 & 15 \\
$B_{5}$ & 1367 & 676 & 1281 & 1281 & 1283 & 10 \\
$B_{1}$ & 1368 & 680 & 1290 & 1290 & 1286 & 5 \\
$B_{1}-B_{120}$ & 36 & 63 & 156 & 114 & 109 & 1 \\
$B_{1}-B_{120}$ & .03 & .09 & .14 & .09 & .08 & \\
\hline$B_{1}$ & & & & & &
\end{tabular}

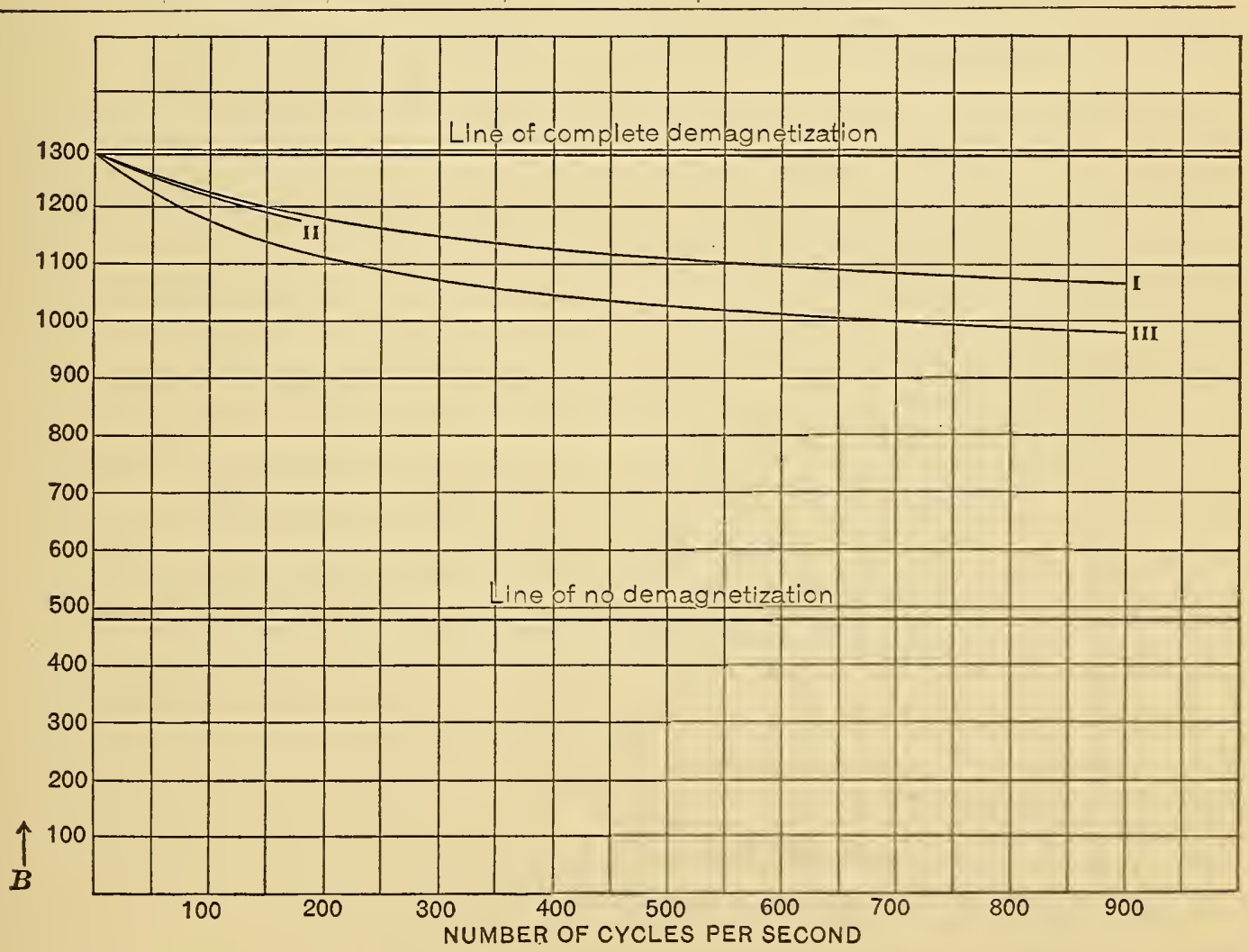

Fig. 11.-Showing the infuence of the demagnetizing frequency on the apparent induction of annealed transformer iron for $H=0.5$.

I without yokes; II with equisectional yokes; III with massive yokes. 
and with the massive yokes, respectively. Graphic representations of the data for the low and the high carbon steels are given in Figs. I 2 and I3. Table XVII gives a portion of the numerical data for all three of the specimens in a form which facilitates comparison. From the graphic and numerical data given above a number of conclusions may be drawn.

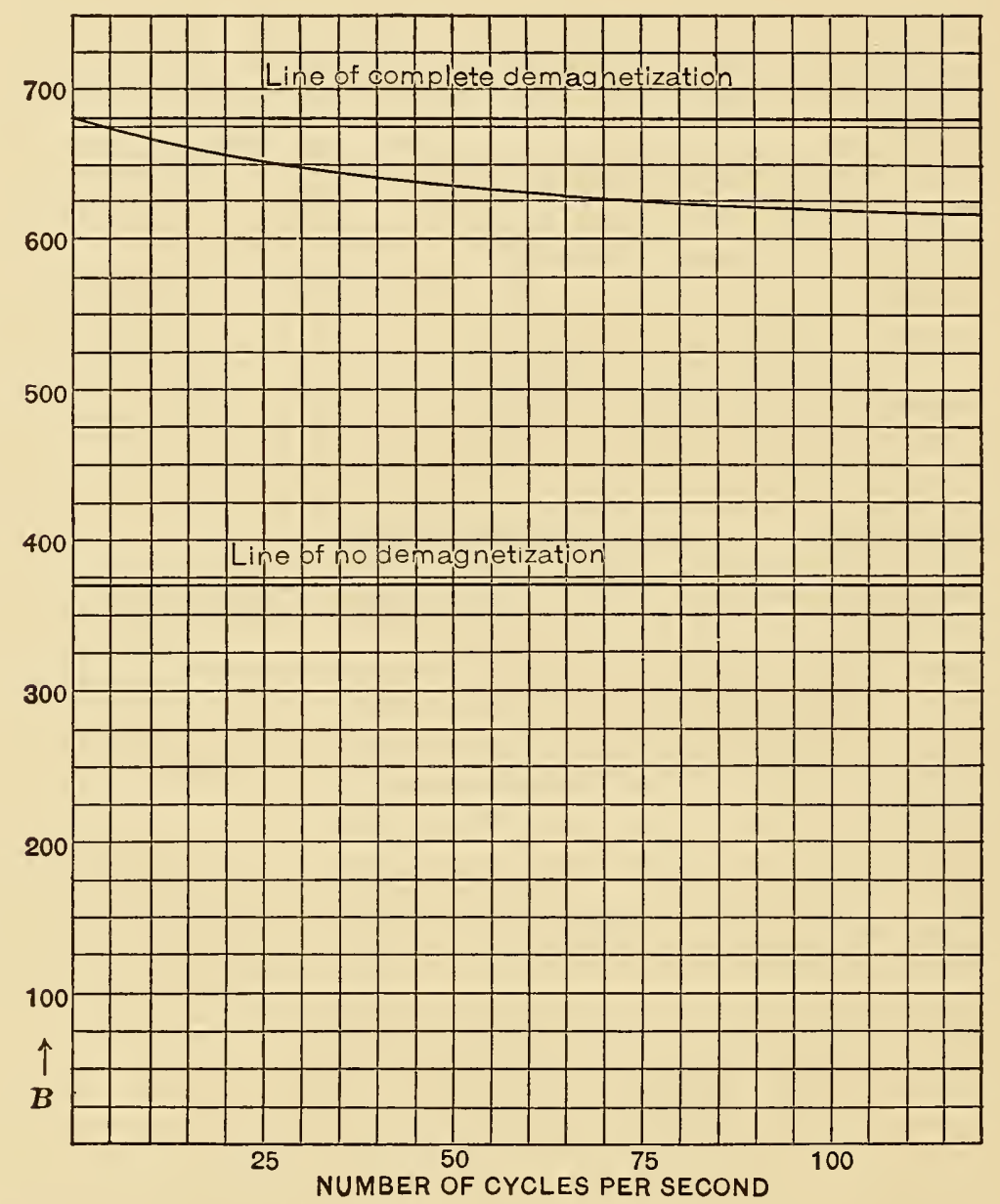

Fig. 12.-Showing the infuence of the demagnetizing frequency on the apparent induction of low carbon steel for $H=2$.

(I) In every case an increase in the frequency of the demagnetizing current is accompanied by a decrease in the apparent induction as subsequently measured.

(2) In the case of the transformer iron, the polarization effect which is measured by the distance of the curve below the upper horizontal line is greater as the cross section of the yokes increases. That the polarization effect does not vanish when the yokes are 
removed shows that while the yokes modify its magnitude, they are not the cause of it. In comparing the transformer iron with the other specimens the data obtained with the massive yokes should be used, as heavy yokes were used on the other specimens.

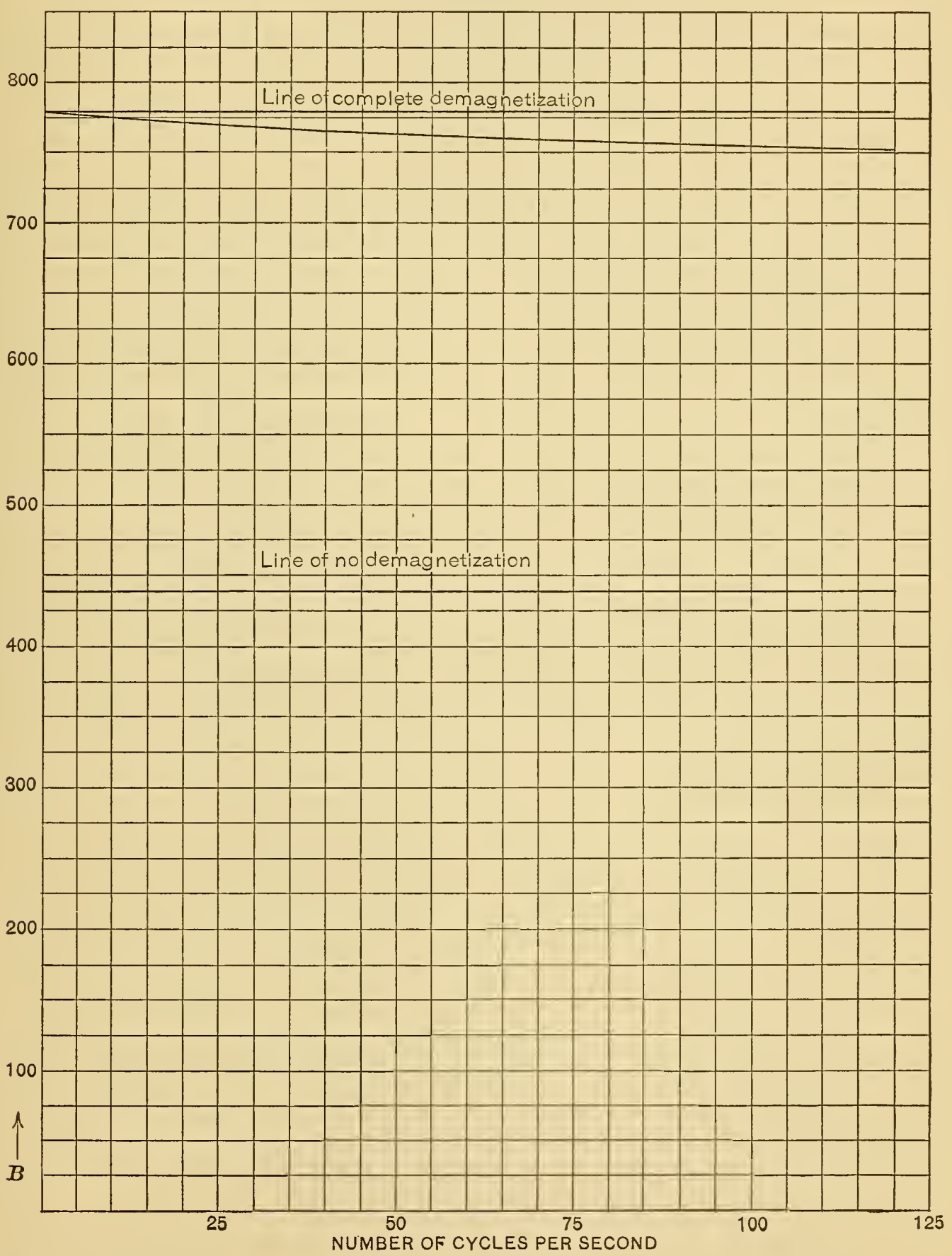

Fig. 13.-Showing the influence of the demagnetizing frequency on the apparent induction of high carbon steel for $H=5$.

II $737-07-5$ 
(3) The diminution in apparent induction-that is, the polarization effect-is relatively greater in the softer material. This statement holds also for the maximum polarization effect, as measured by the distance between the line of perfect demagnetization and the line of no demagnetization. The rate of increase of the polarization effect with the frequency of the demagnetizing current is greater in the softer materials.

\section{TABLE XVIII.}

Showing the nature of the polarization effect remaining in annealed transformer iron after demagnetizing by alternating current of 60 cycles.

\begin{tabular}{|c|c|c|c|c|c|}
\hline \multicolumn{2}{|c|}{ Limits of demagnetizing force } & $* 5-.2$ & $3.5-.2$ & $2.6-.2$ & \multirow{3}{*}{$\underset{\text { zation }}{\text { Nodemagneti }}$} \\
\hline Time inter & & 77 & $5^{8}$ & 34 & \\
\hline \multicolumn{2}{|c|}{ Number of cycles } & 4620 & 3480 & 2040 & \\
\hline$H$ & $\begin{array}{l}\text { Normal } \\
\text { induction }\end{array}$ & \multicolumn{4}{|c|}{ Polarization effects } \\
\hline .3 & 370 & 20 & 30 & 30 & 240 \\
\hline .4 & 670 & 30 & 30 & 40 & 440 \\
\hline .5 & 1290 & 50 & 50 & 70 & 810 \\
\hline .6 & 1680 & 60 & 60 & 90 & 960 \\
\hline .7 & 2570 & 80 & 80 & 100 & 1190 \\
\hline .8 & 3370 & 70 & 70 & 70 & 860 \\
\hline .9 & 4300 & 60 & 60 & 60 & 600 \\
\hline 1.0 & 5130 & 50 & 50 & 50 & 380 \\
\hline 1.2 & 6730 & 40 & 40 & 40 & 240 \\
\hline 1.4 & 6950 & 20 & 20 & 20 & 90 \\
\hline 1.6 & 7610 & 10 & 10 & 10 & 30 \\
\hline 2.0 & 8880 & 0 & 0 & 0 & 0 \\
\hline
\end{tabular}

* This column holds also for the following conditions:

\begin{tabular}{l|c|c|c|c}
\hline $\begin{array}{l}\text { Limits of demagnet- } \\
\text { izing force }\end{array}$ & $5-.2$ & $20-.2$ & $36-.2$ & $159-.2$ \\
\hline Time interval & 177 & 40.8 & 60 & $5^{2}$ \\
\hline Number of cycles & 4620 & 2448 & 3600 & 3 120 \\
\hline
\end{tabular}


NATURE OF POLARIZATION DUE TO FREQUENCY.

That the above conclusions, based on a single value of the magnetizing force, hold in general is clear from data obtained to show the nature of the polarization effect throughout the whole range of the induction curve. Table XVIII shows such a set of data for the annealed transformer iron where the results are expressed in terms of polarization effects. Several things in this table are worthy of note.

\section{TABLE XIX.}

Showing the nature of the polarization effect remaining in low carbon steel after demagnetizing by an alternating current of 60 cycles per second.

\begin{tabular}{|c|c|c|c|c|c|}
\hline \multicolumn{2}{|c|}{ Limits of demagnetizing force } & $90.1-.2$ & $42.4-.2$ & $16.2-.2$ & \multirow{3}{*}{$\underset{\text { zation }}{\text { No demagneti- }}$} \\
\hline Time inter & & 122.8 & 140.6 & II8 & \\
\hline \multicolumn{2}{|c|}{ Number of cycles } & 7368 & 6436 & 7080 & \\
\hline - $H$ & $\begin{array}{c}\text { Normal } \\
\text { induction }\end{array}$ & \multicolumn{4}{|c|}{ Polarization effects } \\
\hline 1 & 190 & 0 & 12 & 16 & 100 \\
\hline 2 & 680 & 20 & 50 & 85 & 310 \\
\hline 3 & 1930 & 45 & 120 & 200 & 470 \\
\hline 4 & 4150 & 100 & 280 & 420 & 480 \\
\hline 5 & 6790 & 70 & 280 & 300 & 490 \\
\hline 6 & 9140 & 70 & 200 & 210 & 370 \\
\hline 7 & 9990 & 60 & 110 & 140 & 250 \\
\hline 8 & 11070 & 50 & 60 & 90 & 120 \\
\hline 9 & 11880 & 20 & 20 & 20 & 60 \\
\hline 10 & 12470 & 0 & 0 & 0 & 10 \\
\hline
\end{tabular}

Plotted in Fig. I4.

(I) The polarization effect exists for all values of the magnetizing force up to the critical demagnetizing force, but is much smaller than the naximum polarization effect observed after intense magnetization without subsequent demagnetization. In this respect it resembles the effect after the imperfect demagnetization due to the upper limit of the demagnetizing force being too low.

(2) The polarization effect is constant for all values of the initial demagnetizing force greater than 5. A reference to Table VIII will 
show that for slow frequency the maximum demagnetizing force of 2.0 or over gave constant results. An alternating current then requires a greater initial maximum to produce its full effect.

(3) The polarization effect after a demagnetization by alternating current, even when this has a value great enough to produce its maximum effect, is of considerable magnitude and extends from the smallest values of the magnetizing force up to the critical demagnetizing force.

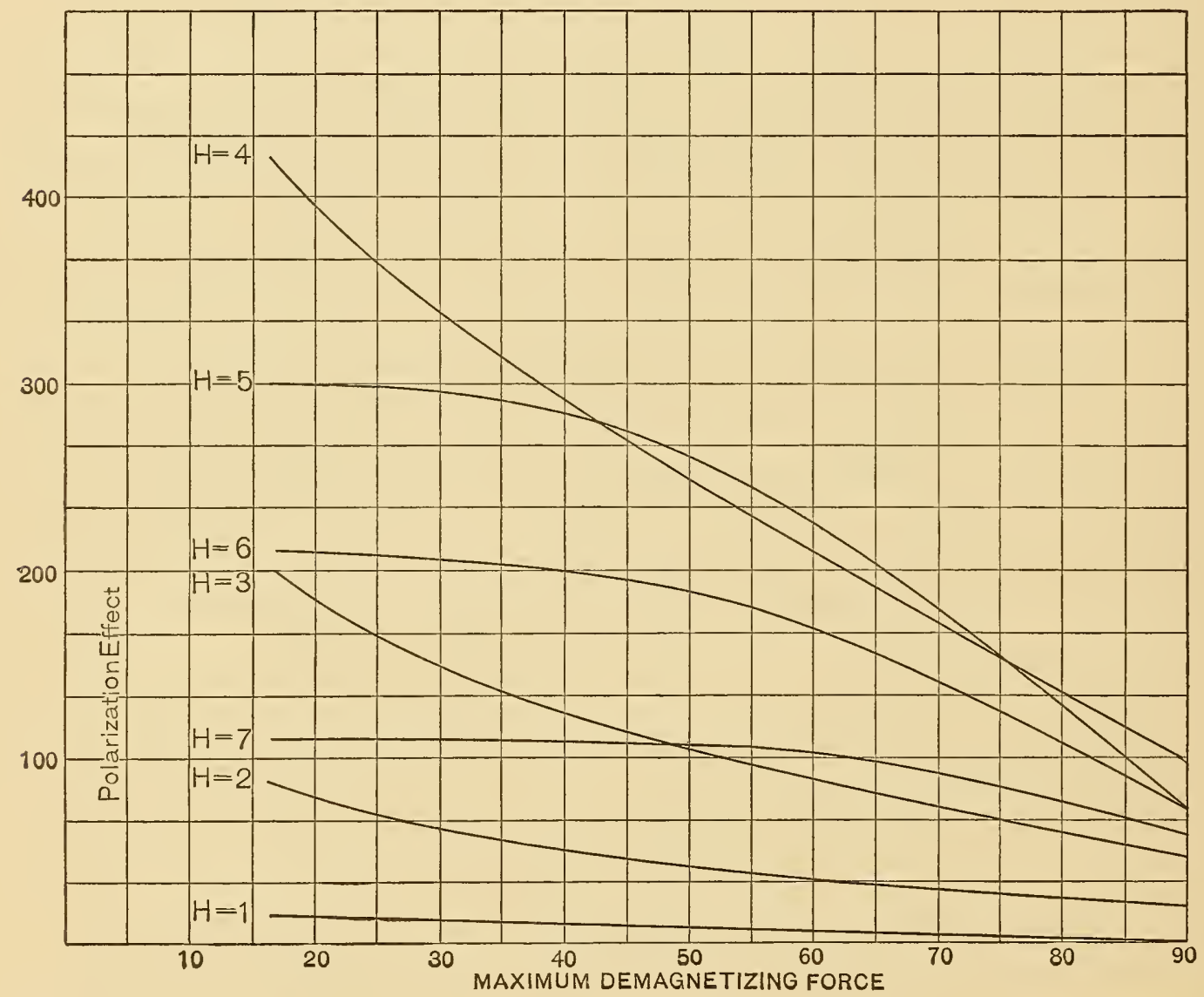

Fig. 14. - Showing how the polarization effect in low carbon steel due to excessive frequency varies with the maximum demagnetizing force.

(Numerical data in Table XIX.)

The low carbon steel was examined in the same way. The data for this have been shown numerically in Table XIX and graphically in Fig. I4. For this specimen also the polarization exists for all values of the magnetizing force up to the critical value. A constant value, however, was not reached at the values of the maximum demagnetizing forces used, even though a value orer six times the maximum required at low frequency was used. 
THE CAUSE-EDDY CURRENTS.

As was expected, the demagnetizing efficiency of an alternating current is less than that of a slowly reversed direct current. This difference is much greater in the thick round rod of low carbon steel than in the thin strip of transformer iron. (See dimensions in Table I.) Referring to Fig. 25 and assuming a mean permeability of 1000 for the round rod we see that the magnetic force on the axis is only 7 per cent of the magnetizing force exerted by the alternating current of 60 cycles. The alternating current furnished a magnet-

TABLE XX.

Showing the influence of eddy currents during the demagnetization by alternating current on the residual polarization effect.

\begin{tabular}{|c|c|c|c|c|c|c|c|}
\hline \multicolumn{2}{|c|}{$\begin{array}{l}\text { Limits of demagretizing } \\
\text { force }\end{array}$} & $15-.2$ & $5.3-.2$ & I7.6--.2 & $28-.2$ & $155-.2$ & $28-.2$ \\
\hline \multicolumn{2}{|c|}{ Time interval } & 96 & 57.2 & 72 & $6 g .8$ & 65.6 & 53.8 \\
\hline \multicolumn{2}{|c|}{ Frequency } & 1.7 & 60 & 60 & 60 & 60 & 120 \\
\hline$H$ & $\begin{array}{l}\text { Normal } \\
\text { induction }\end{array}$ & \multicolumn{6}{|c|}{ Polarization effects } \\
\hline .3 & 370 & 20 & 70 & 30 & 30 & 20 & 40 \\
\hline .4 & 670 & 40 & 130 & 70 & 50 & 50 & 90 \\
\hline .5 & 1290 & 90 & 250 & 120 & 100 & 100 & 170 \\
\hline .6 & 1680 & 110 & 400 & 180 & 160 & 120 & 280 \\
\hline .7 & 2570 & 170 & 620 & 290 & 250 & 230 & 400 \\
\hline .8 & 3370 & 210 & 720 & 320 & 280 & 250 & 460 \\
\hline .9 & 4300 & 220 & 740 & 340 & 300 & 260 & 480 \\
\hline 1.0 & 5130 & 240 & 660 & 350 & 280 & 240 & 500 \\
\hline 1.2 & 6730 & 200 & 480 & 320 & 250 & 240 & 420 \\
\hline 1.4 & 6950 & 150 & 350 & 290 & 200 & 190 & 320 \\
\hline 1.6 & 7610 & 80 & 320 & 250 & 180 & 160 & 300 \\
\hline 2.0 & 8880 & 30 & 240 & 180 & 100 & 100 & 200 \\
\hline
\end{tabular}

Plotted in Fig. 15.

izing force of 30 units, so that in the case of the low carbon steel where the induction does not reach a constant value at the magnetizing forces used, the incompleteness is due to the combined effect of frequency and too low magnetizing current. In the case of the 
annealed iron, however, increased current does not reduce the polarization effect to zero, so that here we have an effect due solely to the frequency.

There seems no doubt that this decrease in induction after demagnetizing by alternating current is mainly an eddy current effect;

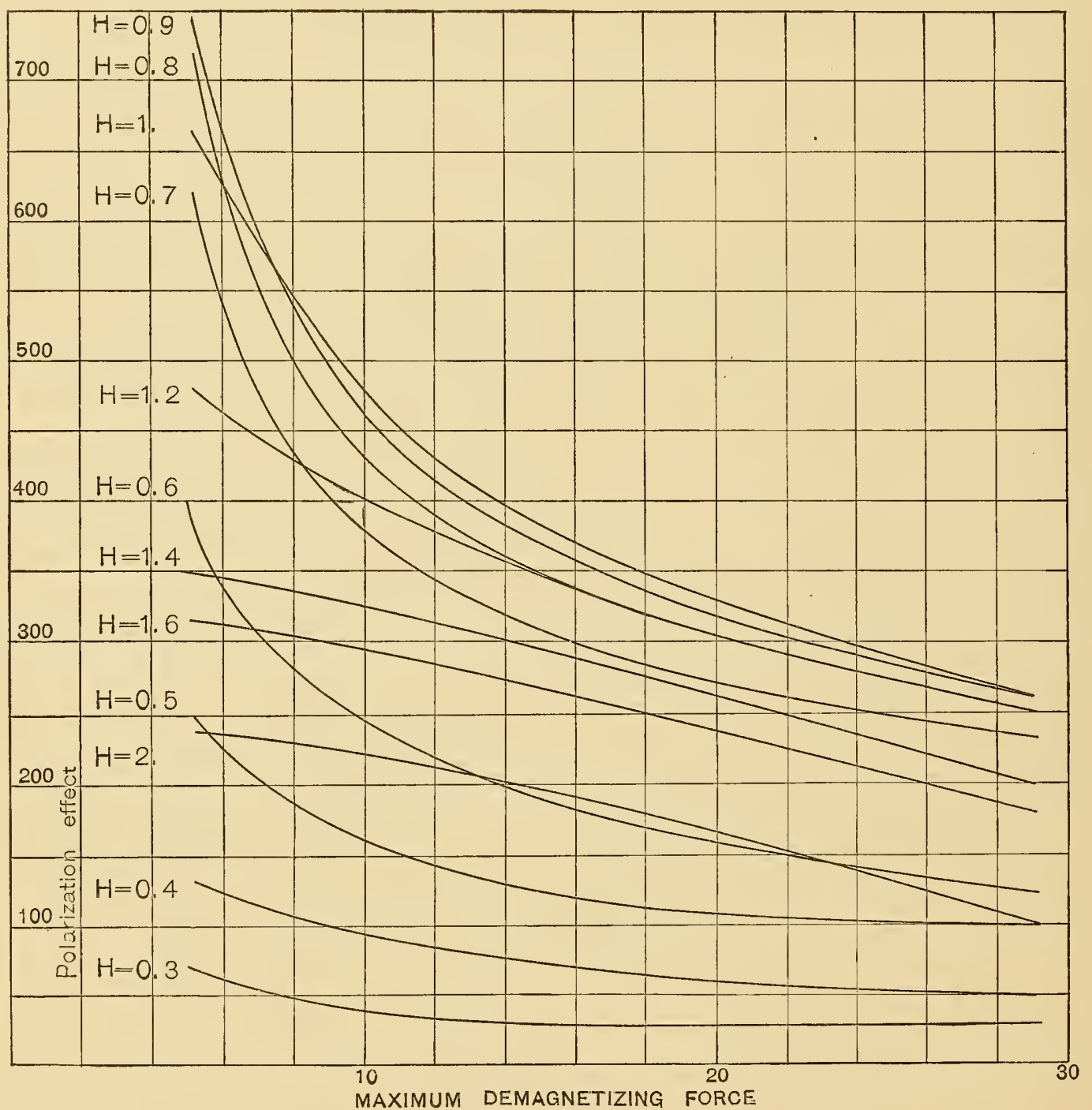

Fig. 15.-Showing how the polarization effect in a specimen of annealed transformer iron surrounded by a copper tube, after demagnetization by an alternating current of 60 cycles, varies with the maximum demagnetizing force.

(Numerical data in Table XX.)

nevertheless, to test this point further, one of the strips of annealed transformer iron was placed in a copper tube and the inductions measured in the regular way after various demagnetizations. The 
data have been expressed as polarization effects and are recorded numerically in Table XX and graphically in Fig. I5. From the table we may draw a number of conclusions.

(I) The polarization effect even after slow reversals is not zero as we should expect it to be for perfect demagnetization.

(2) The polarization after a maximum demagnetizing force of 5 is much greater than it was when the copper tube was off. As the maximum force increases the polarization effect decreases throughout the whole range of magnetizing forces in much the same way as it does when the polarization effect is decreased by carrying the upper limit of a slowly reversed demagnetizing force up nearer and nearer to the critical value. The sixth and eighth columns of this table show that doubling the demagnetizing frequency, other conditions remaining unaltered, approximately doubles the polarization effect.

(3) The curves of Figs. I4 and I5 were drawn primarily to show how the polarization effect decreases as the upper limit of the demagnetizing force increases. The form of these curves is interesting. For the lower values of $H$ these curves are concave upward. As the value of $H$ increases the initial curvature increases, reaches a maximum in the neighborhood of the maximum of the permeability, finally decreases and becomes convex upward for the higher values of $H$. Other data seem to indicate that all of these curves become concave upward for large values of the upper limit of the demagnetizing force.

\section{CONSTANCY OF RESULTS.}

Another and very important fact brought ont during the course of these experiments is the uniform consistency with which results are reproduced. Thus, while an alternating current of a frequency of 90 cycles per second will give a residual polarization effect it always gives the same residual value, and the induction curve obtained after such demagnetization may be repeated any number of times. No evidence of imperfect demagnetization exists except the fact that higher inductions may be obtained under other methods of demagnetization. This probably accounts for the fact that so many experimenters consider an alternating current demagnetization as entirely satisfactory. Furthermore, the polarization effect remain- 
ing after demagnetization by alternating current decreases with decrease in the thickness of the specimen so that in the case of the thin transformer iron, such as that used in this investigation $(.036 \mathrm{~cm})$, or in the work of Professor Searle $(.034 \mathrm{~cm}$ and .037 $\mathrm{cm})$, the error introduced by imperfect demagnetization is negligible except in the steep part of the $B-H$ curve. It is in the case of specimens of large cross section that the objections to alternating current demagnetization have most weight.

\section{TABLE XXI.}

Showing the nature of the residual polarization effect in annealed transformer iron caused by the time interval of demagnetization being too brief.

\begin{tabular}{|c|c|c|c|c|c|}
\hline \multicolumn{2}{|c|}{ Limits of demagnetizing force } & $15-.2$ & $\mathrm{I}_{5}-.2$ & $15-.2$ & \multirow{3}{*}{$\begin{array}{l}\text { No demagnet- } \\
\text { ization }\end{array}$} \\
\hline Time inter & & 74 or over & $5^{8}$ & 20 & \\
\hline \multicolumn{2}{|c|}{ Number of cycles } & Ixo or over & 85 & 27 & \\
\hline$H$ & $\begin{array}{l}\text { Normal } \\
\text { induction }\end{array}$ & \multicolumn{4}{|c|}{ Polarization effects } \\
\hline .3 & 370 & 0 & 10 & 30 & 240 \\
\hline .4 & 670 & 0 & 20 & 70 & 440 \\
\hline .5 & 1290 & 0 & 20 & 80 & 810 \\
\hline .6 & 1680 & 0 & 30 & 100 & 960 \\
\hline .7 & 2570 & 0 & 50 & 150 & 1190 \\
\hline .8 & 3370 & 0 & 40 & 120 & 860 \\
\hline .9 & 4300 & 0 & 40 & 110 & 600 \\
\hline 1.0 & 5130 & 0 & 20 & 60 & 380 \\
\hline 1.2 & 6730 & 0 & 0 & 40 & 240 \\
\hline 1.4 & 6950 & 0 & 0 & 0 & 90 \\
\hline 1.6 & 7610 & 0 & 0 & 0 & 30 \\
\hline 2.0 & 8880 & 0 & 0 & 0 & 0 \\
\hline
\end{tabular}

As a general conclusion from the preceding, it is evident that the best demagnetization is obtained with the slowest reversals. As, however, the curves of Figs. II, I2, and I 3 cut the vertical axis at a value of the induction not far different from the value at a demagnetizing frequency of one cycle per second, we may without sensi- 
ble difference and with great economy of time use a frequency of one cycle per second in practice. The fact that the constant value of the apparent induction after the best dennagnetization which a 6o-cycle current can give is less than the normal induction indicates that something else besides eddy currents is reducing the value of the induction. This something is probably closely related to the phenomenon of magnetic viscosity.

\section{TIME INTERVAL OF DEMAGNETIZATION.}

Having determined the proper frequency and limits for the demagnetizing force it now remains to determine the effect of variations in the time interval of demagnetization. With this in view the iron

TABLE XXII.

Showing the nature of the residual polarization effect in common sheet iron caused by the time interval of demagnetization being too brief.

\begin{tabular}{|c|c|c|c|c|c|c|}
\hline \multicolumn{2}{|c|}{ Limits of demagnetizing force } & $\mathrm{I} 5-.2$ & I $5-.2$ & $15-.2$ & I5. -2 & \multirow{3}{*}{$\begin{array}{c}\text { No demag- } \\
\text { netization }\end{array}$} \\
\hline Time inte & & $5^{8.2}$ or over & 33.6 & 18 & 7 & \\
\hline \multicolumn{2}{|c|}{ Number of cycles } & 82 or over & 53 & 25 & II & \\
\hline$H$ & $\underset{\text { induction }}{\text { Normal }}$ & \multicolumn{5}{|c|}{ Polarization effects } \\
\hline 1 & 263 & 0 & 15 & 18 & 28 & 166 \\
\hline 2 & 1314 & 0 & 26 & 94 & 124 & 818 \\
\hline 3 & 3770 & 0 & 50 & 105 & 130 & 640 \\
\hline 5 & 7890 & 0 & 25 & 35 & 60 & 160 \\
\hline 7 & 10270 & 0 & 0 & 10 & 20 & 140 \\
\hline 10 & 12170 & 0 & 0 & 0 & 0 & 10 \\
\hline 15 & 13160 & 0 & 0 & 0 & 0 & 0 \\
\hline
\end{tabular}

was demagnetized at a slow rate of reversal and between the demagnetizing limits determined upon above. This was done a number of times, varying the time interval of demagnetization; that is, the number of cycles. The numerical results for transformer iron, common sheet iron, and low carbon steel are given in Tables XXI, XXII, and XXIII. From these data it appears that the polarization effect 
is zero for all values of the nnagnetizing force, provided the demagnetization has taken approximately a ininute. If the time is too brief the polarization effect extends over nearly the whole range from the lowest values up to that of the critical demagnetizing force. It increases in magnitude as the time decreases. Too brief a time interval has the same effect as too small a current or too high a

\section{TABLE XXIII.}

Showing the nature of the residual polarization effect in low carbon steel caused by the time interval of demagnetization being too brief.

\begin{tabular}{|c|c|c|c|c|}
\hline \multicolumn{2}{|c|}{ Limits of demagnetizing force } & $15-.2$ & $15-.2$ & \multirow{3}{*}{$\begin{array}{c}\text { No demagneti- } \\
\text { zation }\end{array}$} \\
\hline Time interv & & 75 or over & 67 & \\
\hline \multicolumn{2}{|c|}{ Number of cycles } & 83 or over & 100 & \\
\hline$H$ & Normal induction & \multicolumn{3}{|c|}{ Polarization effects } \\
\hline 1 & 190 & 0 & 0 & 100 \\
\hline 2 & 680 & 0 & 5 & 310 \\
\hline 3 & 1930 & 0 & 20 & 470 \\
\hline 4 & 4150 & 0 & 25 & 480 \\
\hline 5 & 6790 & 0 & 40 & 490 \\
\hline 6 & 9140 & 0 & 25 & 370 \\
\hline 7 & 9990 & 0 & 20 & 250 \\
\hline 8 & 11070 & 0 & 0 & 120 \\
\hline 9 & 11880 & 0 & 0 & 60 \\
\hline 10 & 12470 & 0 & 0 & 10 \\
\hline 15 & 14170 & 0 & 0 & 0 \\
\hline
\end{tabular}

frequency. A comparison of the polarization effect after no demagnetization with that after the briefest interval shows that the greater portion of the polarization effect is wiped out by the first few reversals.

Table XXIV shows the effects of variations in the time interval when the demagnetization is carried on at a somewhat higher frequency. The full effect of the demagnetization while less than before is reached in a shorter interval of time and therefore seens to depend on the number of cycles rather than the time. From this it is 
TABLE XXIV.

Showing how the time interval of demagnetization influences the apparent induction.

\begin{tabular}{|c|c|c|}
\hline \multicolumn{3}{|c|}{ Demagnetizing frequency $=\mathrm{I} 4$} \\
\hline Time interval & Number of cycles & Apparent induction \\
\hline \multicolumn{3}{|c|}{ Annealed transformer iron for $H=.5$} \\
\hline \multicolumn{2}{|c|}{ No demagnetization } & 480 \\
\hline 10 & 140 & 1225 \\
\hline 14 & 196 & 1240 \\
\hline 25 & 350 & 1265 \\
\hline 26 & 364 & 1265 \\
\hline 47 & 658 & 1265 \\
\hline 130 & 1352 & 1265 \\
\hline 273 & 3822 & 1265 \\
\hline 310 & 4340 & 1265 \\
\hline \multicolumn{2}{|c|}{ Normal } & 1290 \\
\hline
\end{tabular}

Low carbon steel for $H=2$

\begin{tabular}{|c|c|c|}
\hline \multicolumn{2}{|c|}{ No demagnetization } & 370 \\
\hline 2.4 & 34 & 640 \\
\hline 3.2 & 45 & 649 \\
\hline 4.2 & 59 & 660 \\
\hline 4.6 & 64 & 661 \\
\hline 7.4 & 104 & 662 \\
\hline 18.0 & 252 & 662 \\
\hline 44.0 & 616 & 662 \\
\hline \multicolumn{2}{|c|}{ Normal } & 680 \\
\hline \multicolumn{3}{|c|}{ High carbon steel for $H=\mathrm{IO}$} \\
\hline \multicolumn{2}{|c|}{ No demagnetization } & 2600 \\
\hline 26 & 364 & 2960 \\
\hline 53 & 742 & 2960 \\
\hline 126 & 1764 & 2960 \\
\hline 221 & 3094 & 2960 \\
\hline \multicolumn{2}{|c|}{ Normal } & 2980 \\
\hline
\end{tabular}


evident that if the time of demagnetization is kept constant while the frequency is varied, there will be a tendency for the induction to increase as the frequency decreases as long as the time interval is great enough to allow the demagnetizing current to accomplish

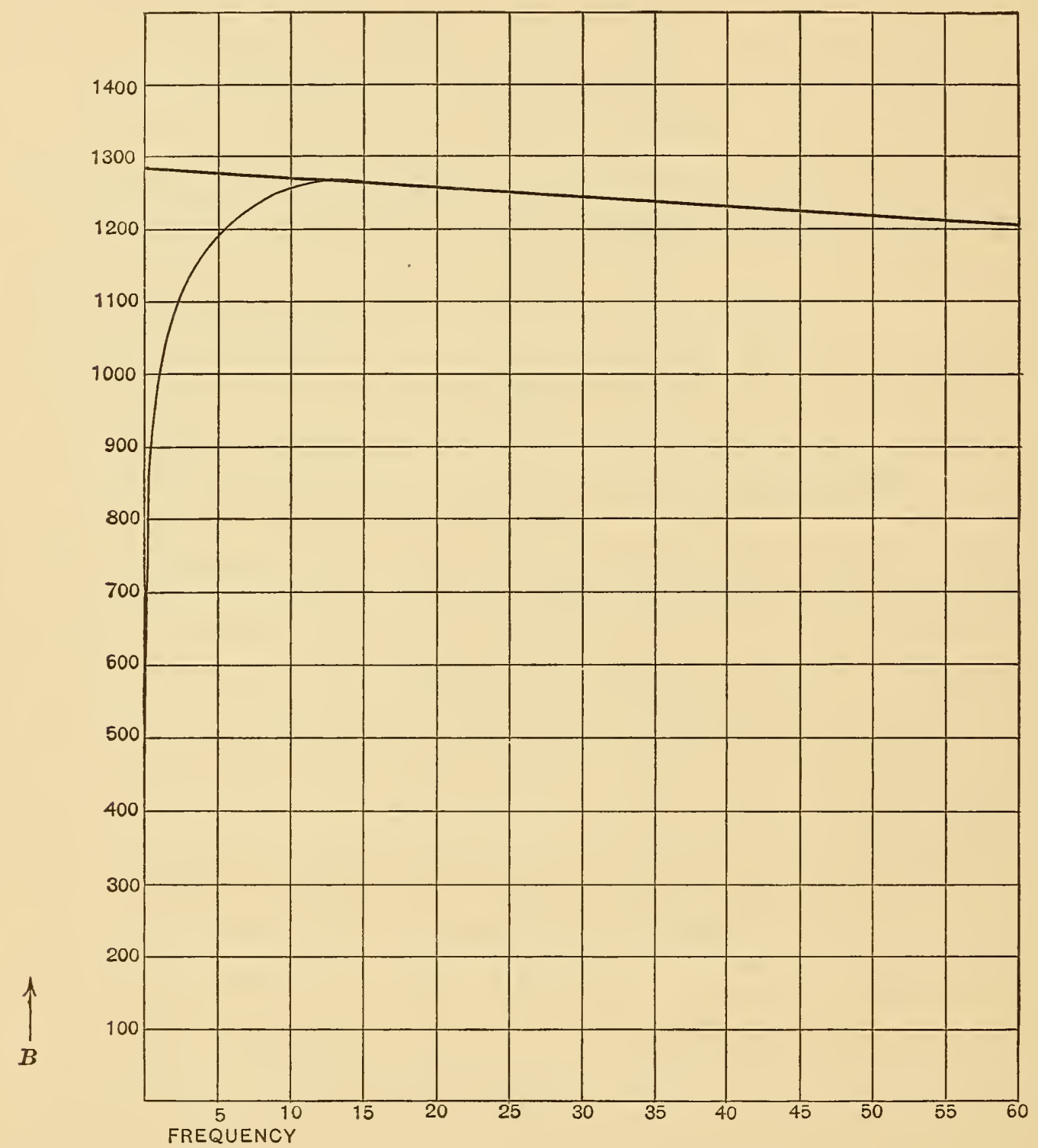

Fig. 16.-Showing the combined effect of frequency and time interval of demagnetization on the apparent induction of transformer iron when $H=0.5$.

its full effect. For the lower frequencies, though a greater efficiency is possible, a longer time is required, and if this is too short the effect of the briefness may exceed the advantage due to the slower frequency and the induction diminishes from a certain point on as 
the frequency decreases. This is exactly what happened in one of the earlier experiments of this investigation. A portion of the data obtained is shown graphically in Fig. I6. This curve led to the erroneous conclusion that a frequency of fourteen cycles per second was the best frequency for the demagnetizing current.

THE NORMAL INDUCTION.

After the iron has been thus freed from all traces of previous magnetic polarization it is ready for the ballistic determination.

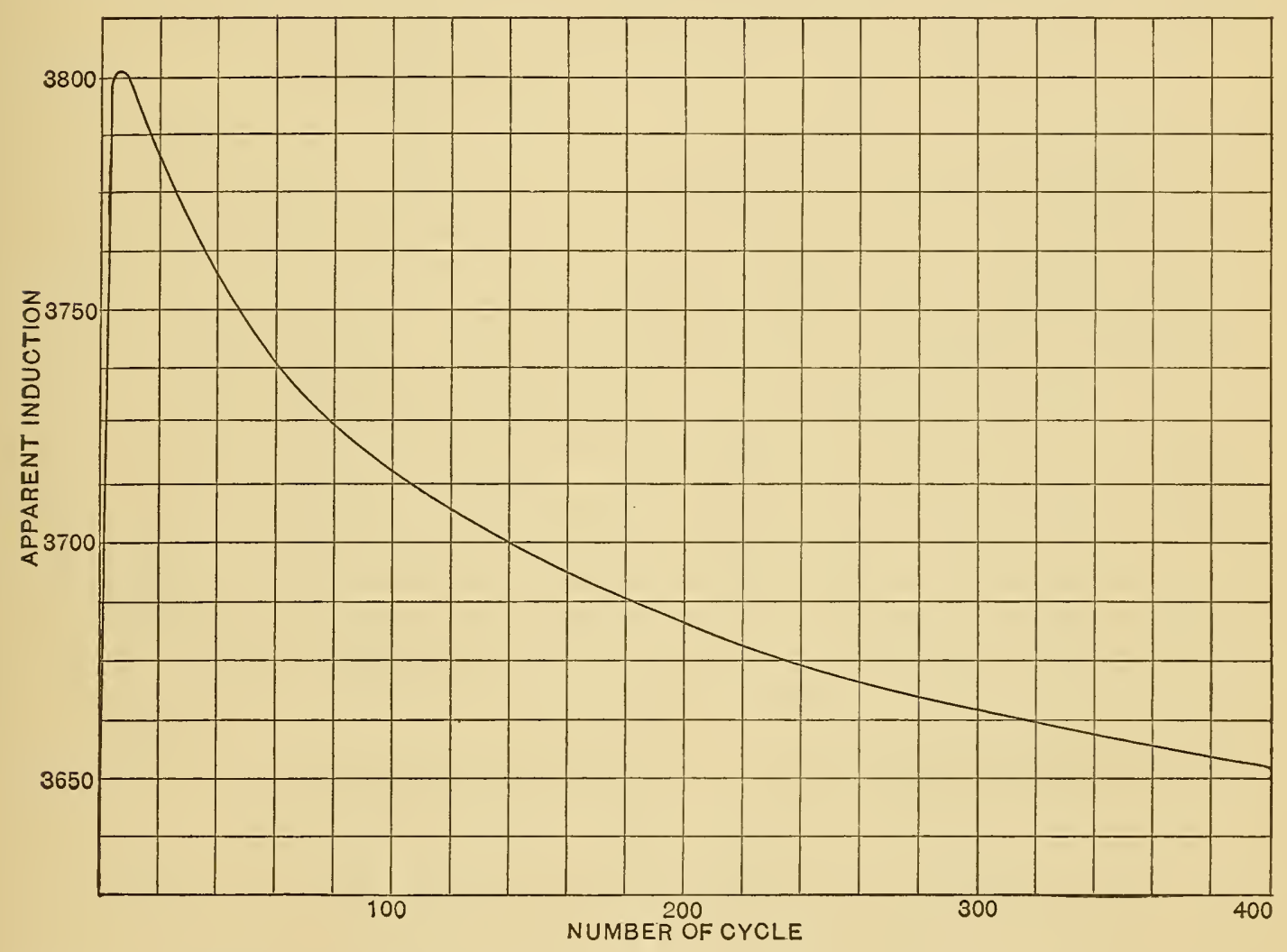

Fig. 17.-Showing the manner in which the apparent induction of an iron ringchanges on successive reversals of the magnetizing force.

We have earlier defined true induction as the normal cyclic induction. The reason for this is apparent from the following:

The induction at the point of maximum differential permeability in a bundle of ring stampings of thin annealed transformer iron was determined for successive reversals of the magnetizing force. The results appear in Fig. I7, where the number of the cycle is plotted on the horizontal axis and inductions along the vertical. The ver- 
tical scale is greatly enlarged so as to show the characteristics of the curve. This curve shows three characteristic parts. The first few reversals show a rapidly increasing apparent induction, then a maximum value is passed, and finally the apparent induction decreases, at first quite rapidly, then more and more gradually, and finally approaches a lower limit asymptotically. As the test specimen in this case is an endless ring with the magnetizing coil wound

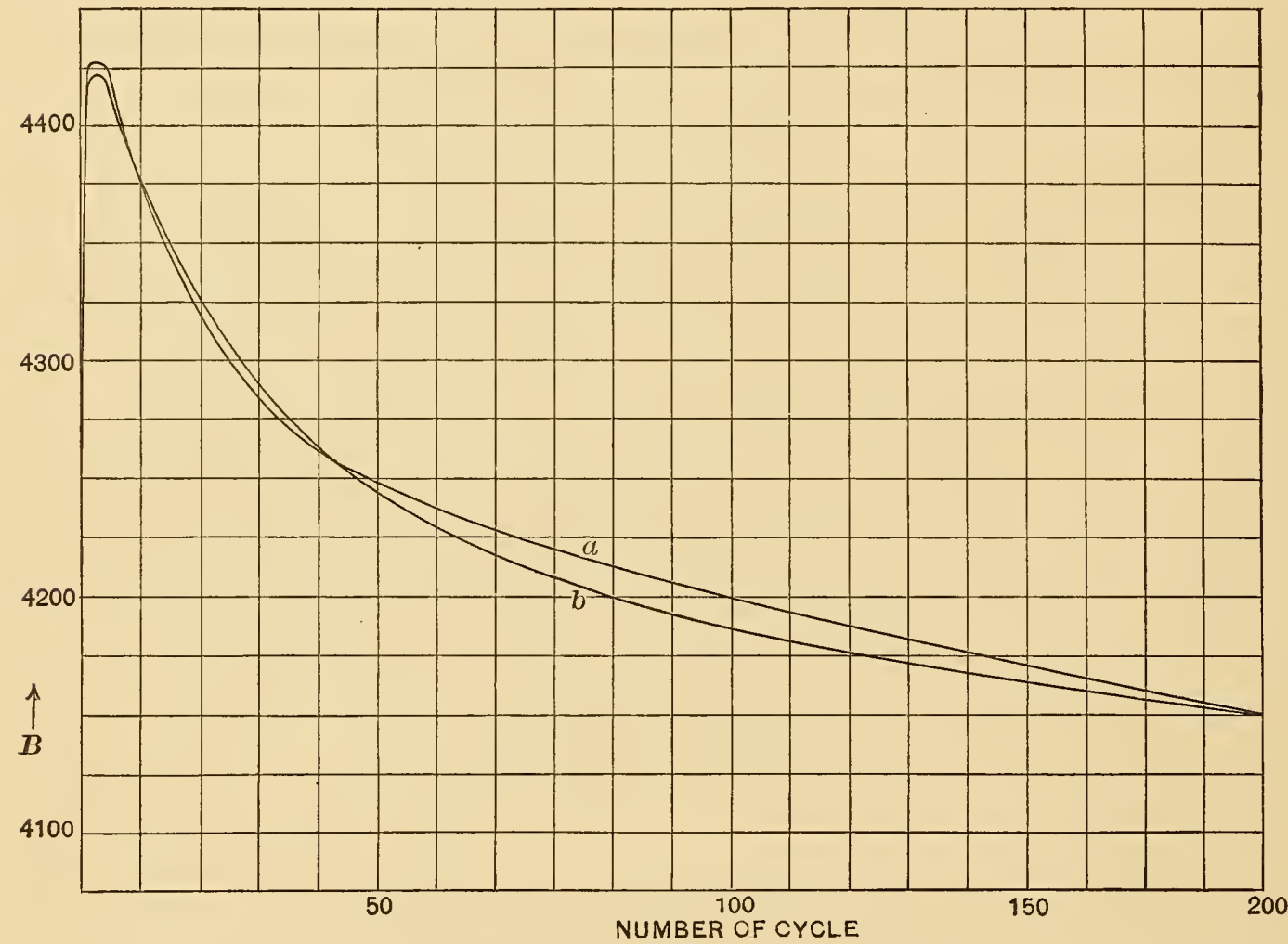

Fig. 18.-Showing the manner in which the apparent induction of low carbon steel changes with successive reversals of the force $H=4$.

(a) with yokes, and (b) without yokes.

uniformly this phenomenon can not be due to any end effect. Similar curves taken with straight rods of low carbon steel are shown in Fig. I8. The curve "a" represents data in which the rods were joined together by yokes, while for curve " $b$ " the rods were not joined but placed as close as the magnetizing coils would allow. These two curves have the same characteristics as the one obtained from the ring. They are so nearly alike that no modifying effect can be attributed to the yokes. To examine more fully the manner in which the cyclic state is reached for various values 
of the magnetizing force, complete induction curves were obtained for several values of the magnetizing force after certain numbers of reversals. This was done for annealed transformer iron, low carbon steel, and high carbon steel, and the data are given in Tables XXV, XXVI, and XXVII, and in part are shown graphically in figures I9, 20 , and 2I. Both from the curves and the summaries at the bottom

TABLE XXV.

Showing the manner in which completely demagnetized transformer iron approaches the cyclic state.

\begin{tabular}{|c|c|c|c|c|c|c|c|}
\hline \multirow{2}{*}{ Number of cycle } & \multicolumn{7}{|c|}{ Apparent induction } \\
\hline & $H=.5$ & $H=1$ & $H=2$ & $H=3$ & $H=5$ & $H=\mathrm{Io}$ & $H=15$ \\
\hline 1 & 1300 & 5350 & 9100 & 10850 & 12800 & 14620 & 15280 \\
\hline 2 & 1325 & 5400 & 9200 & 11000 & 12810 & 14630 & 15290 \\
\hline 3 & 1320 & 5440 & 9210 & 11020 & 12800 & 14630 & 15280 \\
\hline 4 & 1320 & 5470 & 9200 & 11020 & 12780 & 14630 & 15280 \\
\hline 5 & 1320 & 5490 & 9190 & 11010 & 12770 & 14620 & 15280 \\
\hline 20 & 1318 & 5400 & 9100 & 10950 & 12750 & 14620 & 15280 \\
\hline 50 & 1310 & 5300 & 9030 & 10880 & 12750 & 14620 & 15280 \\
\hline 100 & 1302 & 5215 & 8970 & 10810 & 12750 & 14620 & 15280 \\
\hline 200 & 1294 & 5150 & 8915 & 10760 & 12750 & 14620 & 15280 \\
\hline 400 & 1292 & 5140 & 8890 & 10760 & 12750 & 14620 & 15280 \\
\hline 600 & 1290 & 5130 & 8880 & 10750 & 12750 & 14620 & 15280 \\
\hline$B_{\max }$. & 1325 & 5490 & 9210 & 11020 & 12810 & 14630 & 15290 \\
\hline$B_{\text {final }} \ldots \ldots$ & 1290 & 5130 & 8880 & 10750 & 12750 & 14620 & 15280 \\
\hline$B_{\text {max }}-B_{\text {final }}$ & 35 & 360 & 330 & 270 & 60 & 10 & 10 \\
\hline$\frac{B_{\text {max }}-B_{\text {final }}}{B_{\text {final }}}$ & .03 & .07 & .04 & .03 & .00 & .00 & .00 \\
\hline
\end{tabular}

Plotted in Fig. r9.

of the tabulated data it is evident that the difference between the maximum apparent induction and its final value increases in all the specimens as the value of $H$ used approaches that of maximum permeability. This difference in apparent inductions divided by the final apparent induction gives a quotient which is a maximum at approximately the point where the differential permeability is a 
maximum. No marked difference in the manner in which the various specimens approach the cyclic state can be noticed. Any irregularities that occur in the curve indicating the manner of approach are found during the first few cycles, and are due probably to a

\section{TABLE XXVI.}

Showing the manner in which low carbon steel approaches the cyclic state after one initial demagnetization.

\begin{tabular}{|c|c|c|c|c|c|c|c|}
\hline \multirow{2}{*}{ Number of cycle } & \multicolumn{7}{|c|}{ Apparent induction } \\
\hline & $H=\mathbf{I}$ & $H=3$ & $H=4$ & $H=5$ & $H=7$ & $H=\mathrm{ro}$ & $H=\mathrm{I} 5$ \\
\hline 1 & 191 & 1920 & 4210 & 6860 & 10060 & 12450 & 14170 \\
\hline 2 & 192 & 1930 & 4240 & 6890 & 10070 & 12510 & 14180 \\
\hline 3 & 192 & 1940 & 4270 & 6920 & 10070 & 12500 & 14180 \\
\hline 4 & 192 & 1960 & 4280 & 6920 & 10060 & 12500 & 14180 \\
\hline 5 & 192 & 1970 & 4290 & 6925 & 10060 & 12490 & 14180 \\
\hline 6 & 191 & 1980 & 4290 & 6930 & 10060 & 12490 & 14170 \\
\hline 7 & 191 & 1990 & 4290 & 6930 & 10050 & 12490 & 14170 \\
\hline 8 & 190 & 1990 & 4290 & 6930 & 10050 & 12480 & 14170 \\
\hline 9 & 190 & 1985 & 4280 & 6930 & 10050 & 12480 & 14170 \\
\hline 10 & 190 & 1985 & 4280 & 6925 & 10050 & 12470 & 14170 \\
\hline 20 & 190 & 1980 & 4260 & 6905 & 10040 & 12470 & 14170 \\
\hline 50 & 190 & 1970 & 4250 & 6880 & 10030 & 12470 & 14170 \\
\hline 100 & 190 & 1960 & 4220 & 6850 & 10020 & 12470 & 14170 \\
\hline 200 & 190 & 1950 & 4190 & 6810 & 10010 & 12470 & 14170 \\
\hline 400 & 190 & 1940 & 4160 & 6800 & 9990 & 12470 & 14170 \\
\hline 600 & 190 & 1930 & 4150 & 6790 & 9990 & 12470 & 14170 \\
\hline$B_{\max } \ldots \ldots$ & 192 & 1990 & 4290 & 6930 & 10070 & 12510 & 14180 \\
\hline$B_{\text {final }} \ldots \ldots \ldots$ & 190 & 1930 & 4150 & 6790 & 9990 & 12470 & 14170 \\
\hline$B_{\text {max }}-B_{\text {final }} \cdots \ldots$ & 2 & 60 & 140 & 140 & 80 & 40 & 10 \\
\hline$\frac{B_{\text {max }}-B_{\text {final }}}{B_{\text {final }}} \cdots \cdots$ & .01 & .03 & .03 & .02 & .01 & .00 & .00 \\
\hline
\end{tabular}

Plotted in Fig. 20.

small residual polarization which is large enough to modify the first reversal but is soon wiped out by continued reversals. Such irregularities might be expected in accordance with the theory of molecular magnets. In view of the preceding experiments it seems quite proper 
to fix upon the final minimum value of the apparent induction as the definition of the true normal induction. The initial and maximum values are rejected because of their uncertainty and the fact that they can not be verified by repetition without another demag-

\section{TABLE XXVII.}

Showing the manner in which demagnetized high carbon steel approaches the cyclic state under various forces.

\begin{tabular}{|c|c|c|c|c|c|c|}
\hline \multirow{2}{*}{ Number of cycle } & \multicolumn{6}{|c|}{ Apparent induction } \\
\hline & $H=\mathrm{I}$ & $H=2$ & $H=5$ & $H=\mathrm{xo}$ & $H=15$ & $H=40$ \\
\hline 1 & 109 & 254 & 790 & 3130 & 6780 & 11660 \\
\hline 2 & 109 & 254 & 795 & 3160 & 6790 & 11670 \\
\hline 3 & 109 & 254 & 796 & 3190 & 6800 & 11670 \\
\hline 4 & 109 & 254 & 795 & 3190 & 6805 & 11680 \\
\hline 5 & 108 & 254 & 790 & 3190 & 6800 & 11680 \\
\hline 6 & 108 & 252 & 785 & 3170 & 6800 & 11680 \\
\hline 7 & 108 & 252 & 785 & 3150 & 6800 & 11670 \\
\hline 8 & 108 & 250 & 780 & 3140 & 6800 & 11670 \\
\hline 10 & 108 & 249 & 780 & 3140 & 6800 & 11670 \\
\hline 20 & 108 & 249 & 780 & 3130 & 6790 & 11670 \\
\hline 50 & 108 & 249 & 780 & 3100 & 6760 & 11670 \\
\hline 100 & 108 & 249 & 780 & 3050 & 6730 & 11670 \\
\hline 200 & 108 & 249 & 780 & 3020 & 6700 & 11670 \\
\hline 400 & 108 & 249 & 780 & 2990 & 6690 & 11670 \\
\hline 600 & 108 & 249 & 780 & 2980 & 6680 & 11670 \\
\hline 800 & 108 & 249 & 780 & 2980 & 6680 & 11670 \\
\hline$B_{\max } \ldots \ldots \ldots \ldots$ & 109 & 254 & 796 & 3190 & 6805 & 11680 \\
\hline$B_{\text {final }} \cdots \ldots \ldots \ldots$ & 108 & 249 & 780 & 2980 & 6680 & 11670 \\
\hline$B_{\max }-B_{\text {final }} \cdots$ & 1 & 5 & 16 & 210 & 125 & 10 \\
\hline$\frac{B_{\mathrm{max}}-B_{\text {final }}}{B_{\text {fiual }}} \cdots \cdots$ & .01 & .02 & .02 & .07 & .02 & .00 \\
\hline
\end{tabular}

Plotted on Fig. 2I.

netization. These reasons apply whether the induction is to be measured ballistically or magnetometrically, and if results are to be compared by these two methods care must be taken that the inductions have been measured under the same conditions.

I $73.37-07-6$ 


\section{ONE DEMAGNETIZATION SUFFICIENT.}

It has been suggested by Searle that the specimen should be demagnetized before each determination of an induction. We have already shown that after demagnetization the cyclic induction at

\section{TABLE XXVIII.}

Showing the manner in which low carbon steel approaches a cyclic state under various forces, when it has been demagnetized before each new force is applied.

\begin{tabular}{|c|c|c|c|c|c|c|}
\hline \multirow{2}{*}{ Number of cycle } & \multicolumn{6}{|c|}{ Apparent induction } \\
\hline & $H=\mathrm{I}$ & $H=3$ & $H=4$ & $H=5$ & $I=7$ & $H=$ Iо \\
\hline Make & 190 & 1900 & 4200 & 6800 & 9980 & 12460 \\
\hline 1 & 191 & 1920 & 4250 & 6890 & 10000 & 12500 \\
\hline 2 & 191 & 1910 & 4260 & 6890 & 10010 & 12500 \\
\hline 3 & 191 & 1920 & 4270 & 6900 & 10040 & 12510 \\
\hline 4 & 192 & 1950 & 4290 & 6900 & 10080 & 12510 \\
\hline 5 & 192 & 1970 & 4290 & 6910 & 10080 & 12520 \\
\hline 6 & 191 & 2000 & 4300 & 6920 & 10060 & 12520 \\
\hline 7 & 190 & 2010 & 4300 & 6920 & 10060 & 12510 \\
\hline 8 & 190 & 2010 & 4290 & 6930 & 10060 & 12510 \\
\hline 9 & 190 & 2000 & 4290 & 6930 & 10050 & 12510 \\
\hline 10 & 190 & 2000 & 4280 & 6930 & 10050 & 12500 \\
\hline 20 & 190 & 1990 & 4260 & 6910 & 10040 & 12470 \\
\hline 50 & 190 & 1980 & 4250 & 6890 & 10030 & 12470 \\
\hline 100 & 190 & 1960 & 4230 & 6850 & 10020 & 12470 \\
\hline 200 & 190 & 1950 & 4190 & 6810 & 10010 & 12470 \\
\hline 400 & 190 & 1940 & 4160 & 6800 & 10000 & 12470 \\
\hline 600 & 190 & 1930 & 4150 & 6790 & 9990 & 12470 \\
\hline$B_{\max } \cdots \ldots$ & 192 & 2010 & 4300 & 6930 & 10080 & 12520 \\
\hline$B_{\text {final }} \ldots \ldots$ & 190 & 1930 & 4150 & 6790 & 9990 & 12470 \\
\hline$B_{\text {max }}-B_{\text {final }} \ldots$ & 2 & 80 & 150 & 140 & 90 & 50 \\
\hline$\frac{B_{\text {max }}-B_{\text {final }}}{B_{\text {final }}} \cdots \cdots$ & .01 & .04 & .04 & .02 & .01 & .00 \\
\hline
\end{tabular}

any magnetizing force is not affected by any preceding application of smaller forces; but as this is an important detail of manipulation it is desirable to leave no uncertainty. Two sets of data were there- 
fore obtained-one for a single demagnetization and another in which the specimen was demagnetized before each measurement of the induction. The two sets of data are given in the Tables XXVI and XXVIII.

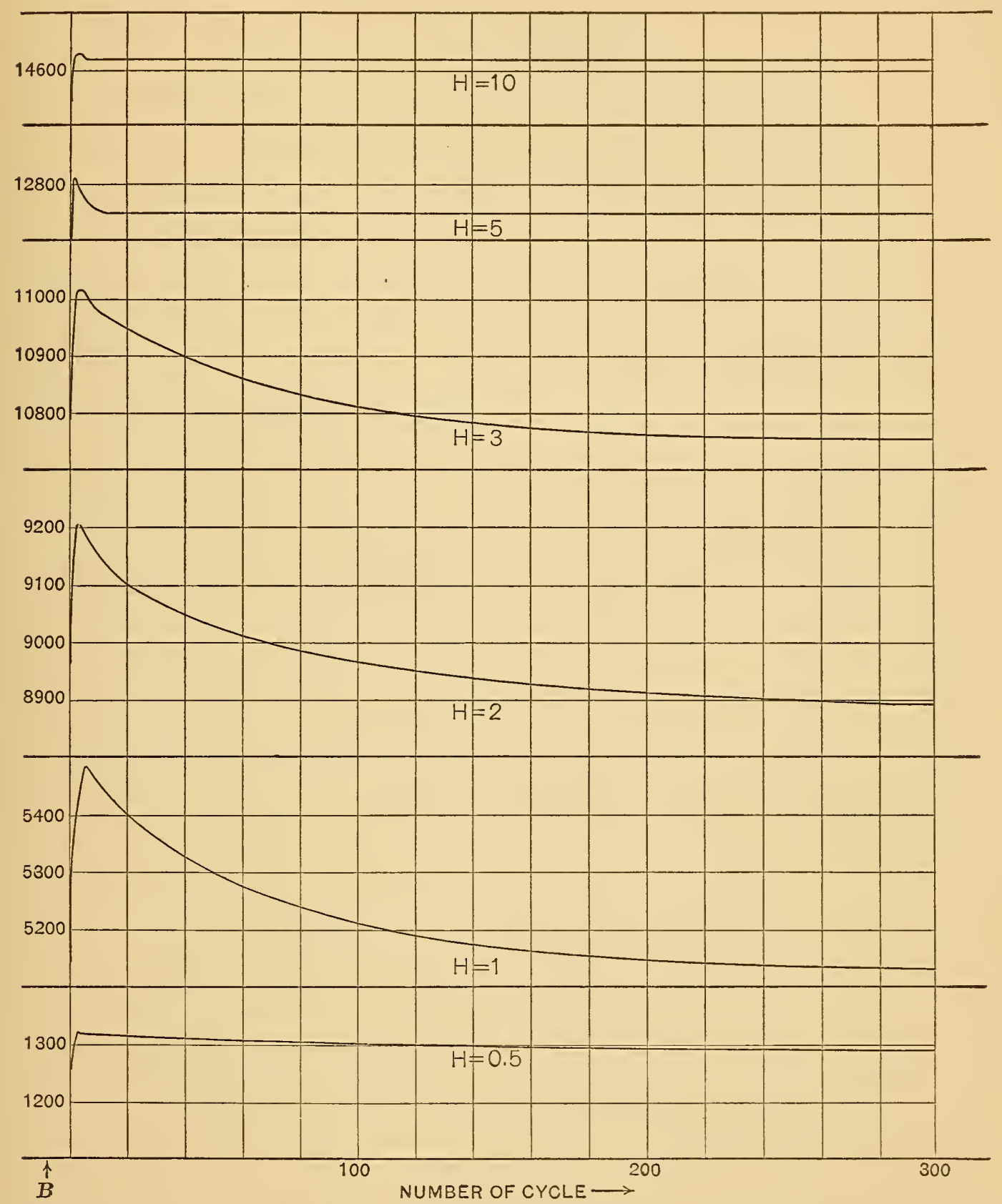

Fig. 19.-Showing the manner in which demagnetized transformer iron approaches the cyclic state for various values of $H$.

(Numerical data in Table XXV.)

The final values of the induction are the same in each case, and the main characteristics of the manner of approach to the cyclic state 
are maintained in each. Whatever differences there are occur in the earlier reversals. This is another argument in favor of the final value as the normal one.

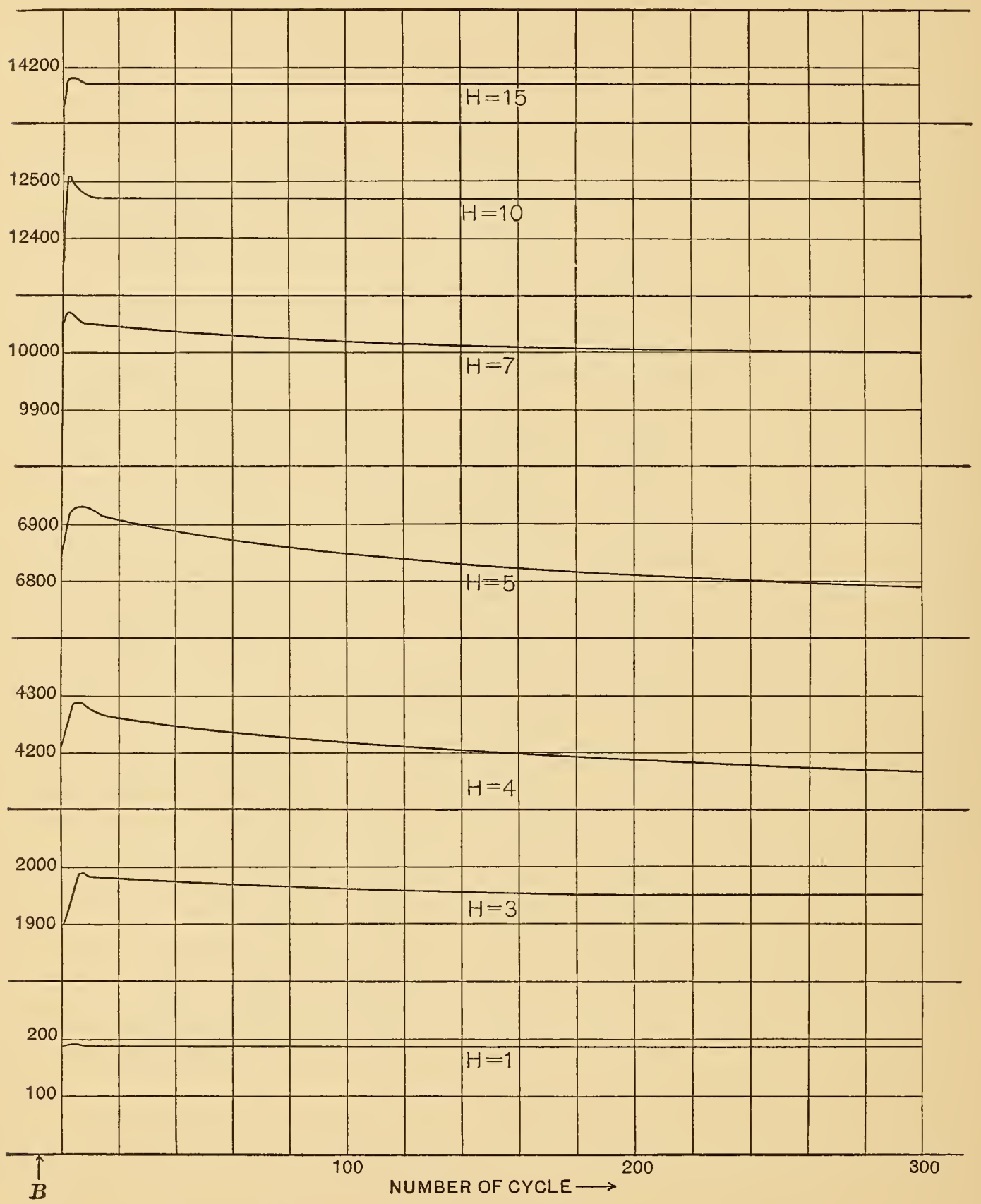

Fig. 20.-Showing the manner in which demagnetized low carbon steel approaches the cyclic state for various values of $H$.

(Numerical data in Table XXVI.) 


\section{EFFECT OF VISCOSITY.}

Fig. 22 shows the manner of approach to the cyclic state under two circumstances. The upper curve shows how a specimen of

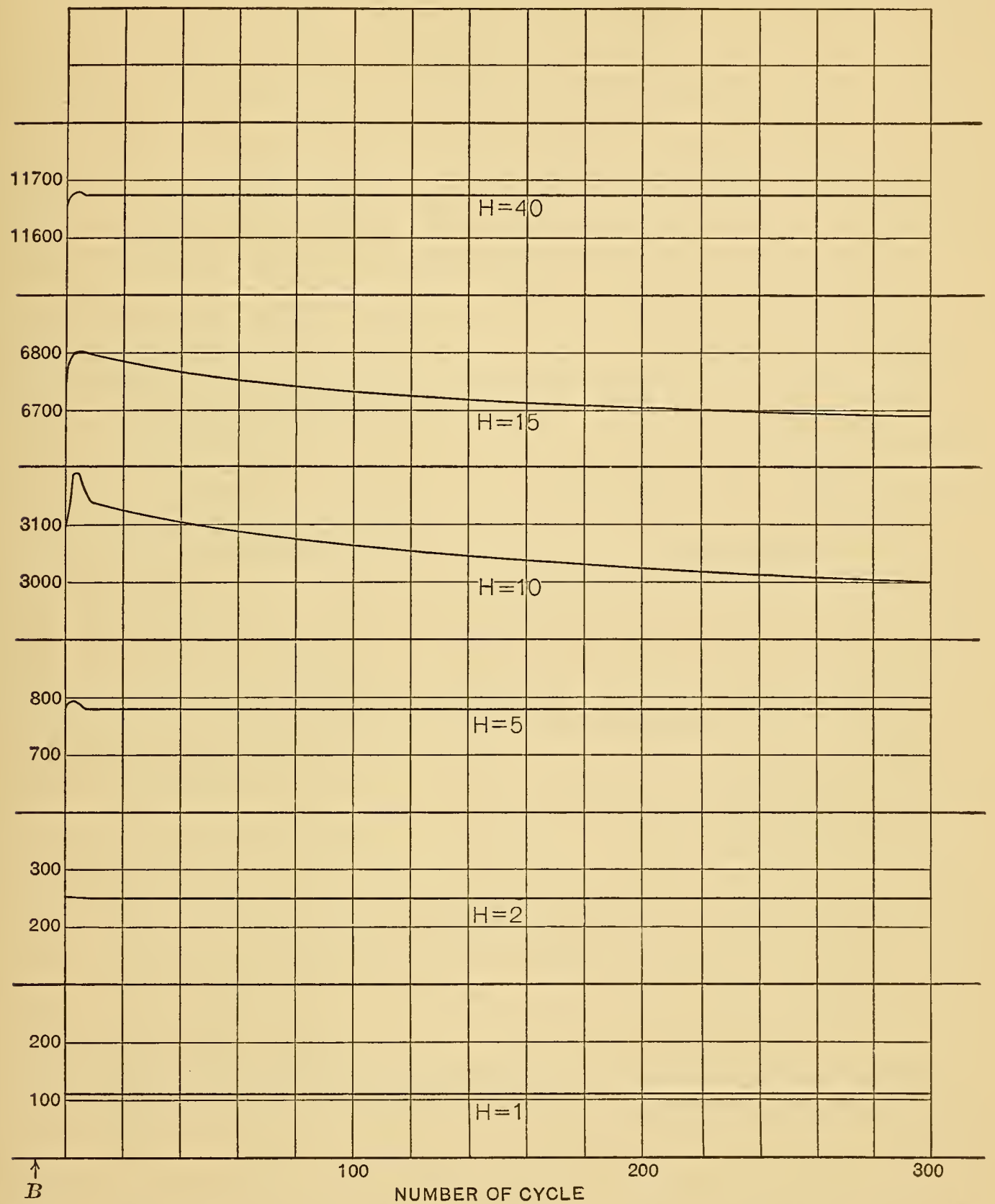

Fig. 21.-Showing the manner in which demagnetized high carbon steel approaches the cyclic state for various values of $H$.

(Numerical data in Table XXVII.)

high carbon steel comes to a cyclic state on repeated reversals of the magnetizing force by hand switch. The solid portion of the curve 
just below this shows apparent inductions as actually observed after imperfect demagnetization. Between the solid portions of this curve reversals were made quite rapidly-several times per second. The dash lines give the hypothetical curve the apparent induction would have followed if the apparent induction had been measured for each reversal and no rapid reversals had been made. There are two causes of irregularities in the curve showing the manner of approach

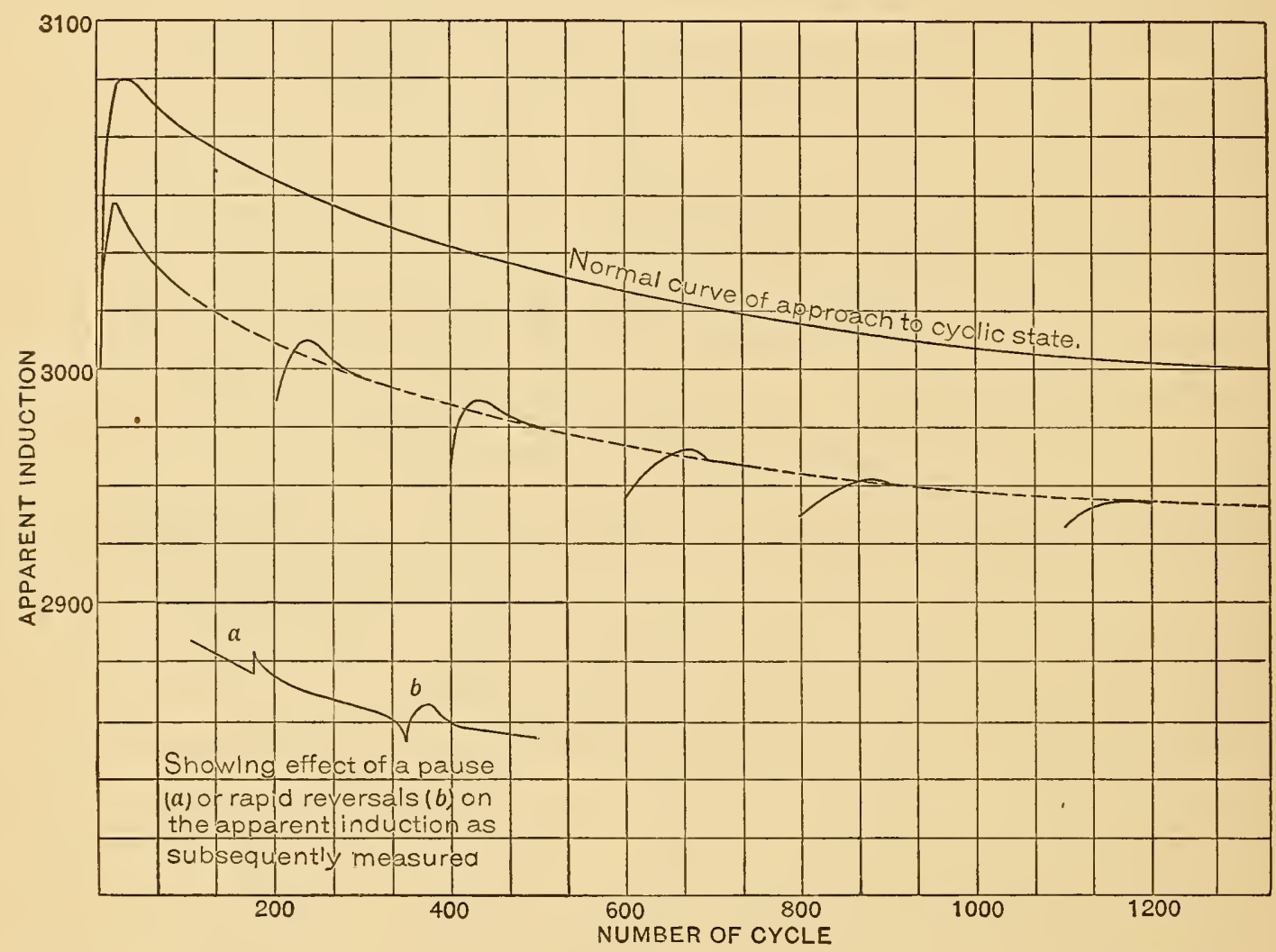

Fig. 22.- Showing how the manner of approach to the cyclic state in high carbon steel is modified by rapid reversals of the magnetizing force and by long pauses.

to the cyclic state. A pause at any point in the curve causes the apparent induction of the succeeding reversal to be a little larger than the one immediately preceding. This is most pronounced in the softer materials and for any specimen is greatest in the steep part of the induction curve and disappears almost completely in the upper parts of this curve. It is noticeable even after the iron has reached a cyclic state under normal conditions. The phenomenon may be attributed to magnetic viscosity. The connection is made clear from the following figure. (Fig. 23). Suppose the iron 
has been subjected to forces of $+H$ and $-H$ alternately at the rate of one reversal per second. Then it will trace a hysteresis loop having its vertices at two symmetrical points as $A$ and $B$. If, however, the reversals are interrupted when the iron is at the point $A$, the steady application of the force will cause the induction to creep from $A$ to $A^{\prime}$. After this creeping has ceased a reversal of the magnetizing force will bring the state point down to $B$. A further pause will again show a creeping from $B$ down to $B^{\prime}$, which is symmetric with $\mathrm{A}^{\prime}$. A magnetometric measurement would take account of this creeping and would measure the induction $\mathrm{Oa}^{\prime}$. A ballistic measurement however would indicate only the portion Oa, the remainder aa' being lost on account of its slowness. This is on the assumption that a ballistic galvanometer with sufficient torsion in its suspension to bring its movable system back to zero is used. An instrument whose movable system has no directive force, such as the Grassot fluxmeter, would measure the full induction as completely as the magnetometer. However, even with an ordinary ballistic galvanometer this full induction

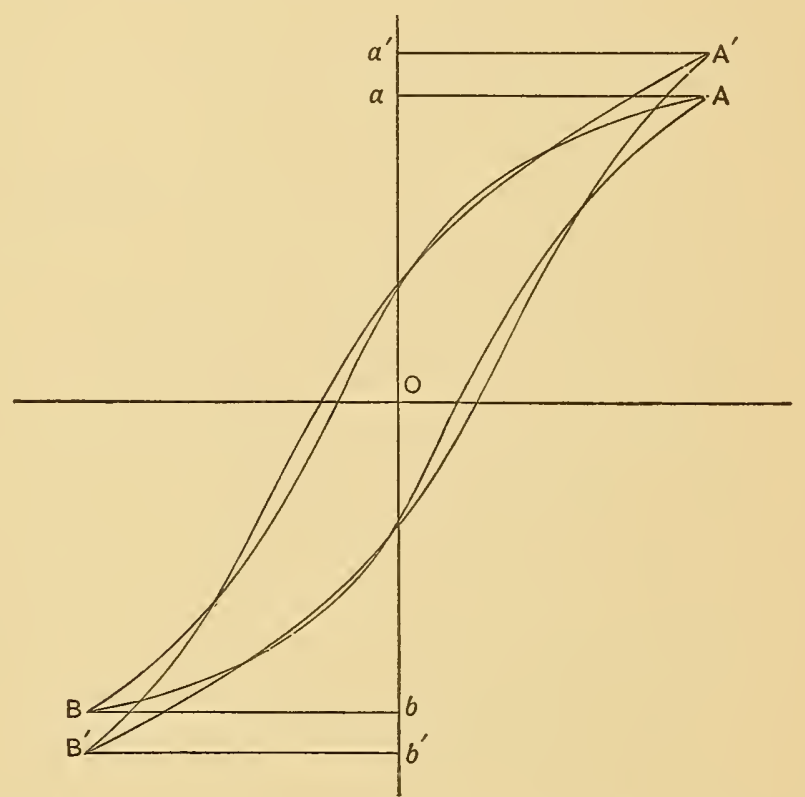

Fig. 23. - Ideal curve to illustrate the effect of magnetic viscosity on the apparent induction. can be determined. Let a ballistic deflection betaken when the iron is traversing the cycle AB. This will be proportional to ba. After a pause take the deflection on the return reversal. This will be proportional to $a^{\prime} b$. The second deflection exceeds the first by $a a^{\prime}$, which is the amount of creeping at one end of the cycle. The full induction would therefore be proportional to ba+2aa'. As this creeping is greatest in the steep part of the $B-H$ curve a single determination here will tell whether it is of sufficient magnitude to warrant consideration. In some of the irons measured it has amounted to as much as I per cent. 
Another irregularity in the curve showing the manner of approach to the cyclic state is the peculiar effect of several rapid reversals. After such treatment the first inductions are too low, then the succeeding ones are too high, but after some slow reversals the inductions show no sign of irregularity. The two kinds of irregularity are shown graphically in the lower corner of Fig. 22.

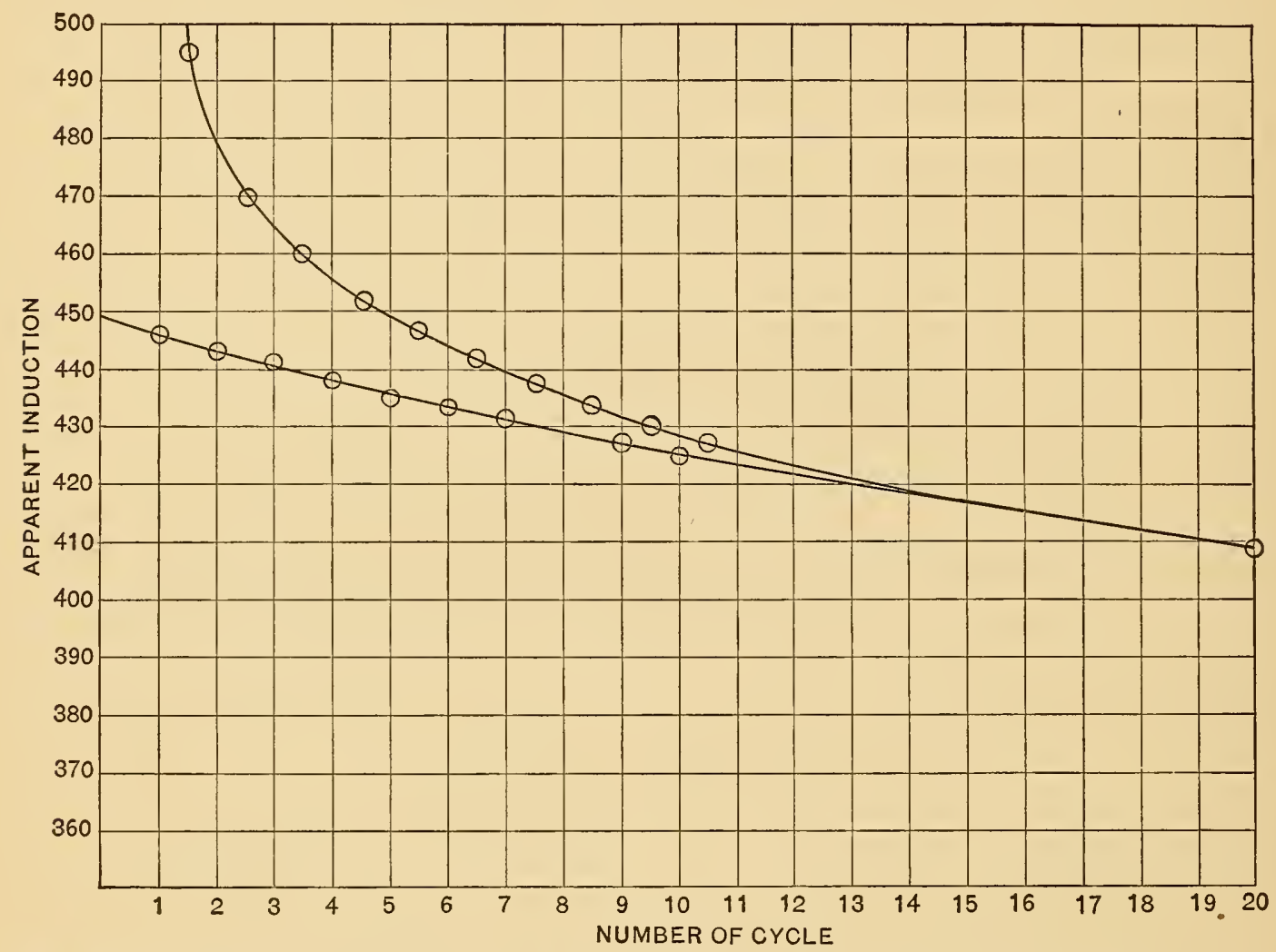

Fig. 24.- Showing the manner in which a highly polarized bar of low carbon steel approaches the cyclic state on repeated reversals of a force $H=2$.

(Numerical data in Table XXIX.)

\section{EFFECT OF REPETITION.}

One might suppose that a sufficient number of reversals of the magnetizing force would obviate the necessity of demagnetization. This is not the case, however, as is seen from the manner in which a specimen of low carbon steel approaches the cyclic state after intense polarization by a force of Ioo. The data for this experiment are shown numerically in Table XXIX and graphically in Fig. 24. The inductions on successive reversals do not form a smooth curve as those obtained after complete demagnetization would, but 
those inductions obtained by reversing the magnetizing force from the direction in which the strong polarization was applied are greater than those due to either the preceding or the following reversals in the opposite direction. Thus Fig. 24 shows two lines, converging after about twenty reversals. As the reversals continue the apparent induction becomes gradually smaller, differing

\section{TABLE XXIX.}

Showing the manner in which a highly polarized piece of low carbon steel approaches the cyclic state.

\begin{tabular}{|c|c|c|c|}
\hline \multicolumn{4}{|c|}{ Polarizing force, roo; Cyclic force, 2} \\
\hline Number of cycle & Apparent induction & Number of cycle & Apparent induction \\
\hline$\frac{1}{2}($ make $)$ & 2500 & $7 \frac{1}{2}$ & 438 \\
\hline 1 (reverse) & 446 & 8 & 429 \\
\hline $1 \frac{1}{2}$ (reverse) & 495 & $8 \frac{1}{2}$ & 437 \\
\hline 2 & 443 & 9 & 427 \\
\hline $2 \frac{1}{2}$ & 470 & $9 \frac{1}{2}$ & 430 \\
\hline 3 & 441 & 10 & 425 \\
\hline $3 \frac{1}{2}$ & 460 & $10 \frac{1}{2}$ & 427 \\
\hline 4 & 438 & 20 & 409 \\
\hline $4 \frac{1}{2}$ & 452 & $20 \frac{1}{2}$ & 409 \\
\hline 5 & 435 & 50 & 388 \\
\hline $5 \frac{1}{2}$ & 447 & 100 & 376 \\
\hline 6 & 433 & 200 & 370 \\
\hline $6 \frac{1}{2}$ & 442 & 1200 & 370 \\
\hline 7 & 431 & Normal induction & 680 \\
\hline
\end{tabular}

Plotted on Fig. 24.

more and more from the normal induction. After 200 cycles (400 reversals) the apparent induction has reached a minimum which a thousand double reversals do not alter. In another case a bar of polarized iron was subjected to slow reversals of the magnetizing force for four hours and yet showed no increase in the apparent induction. 


\section{STRONG VIBRATIONS.}

While the study of magnetism was yet in its infancy Gilbert discovered that a soft iron bar could be quite strongly magnetized by

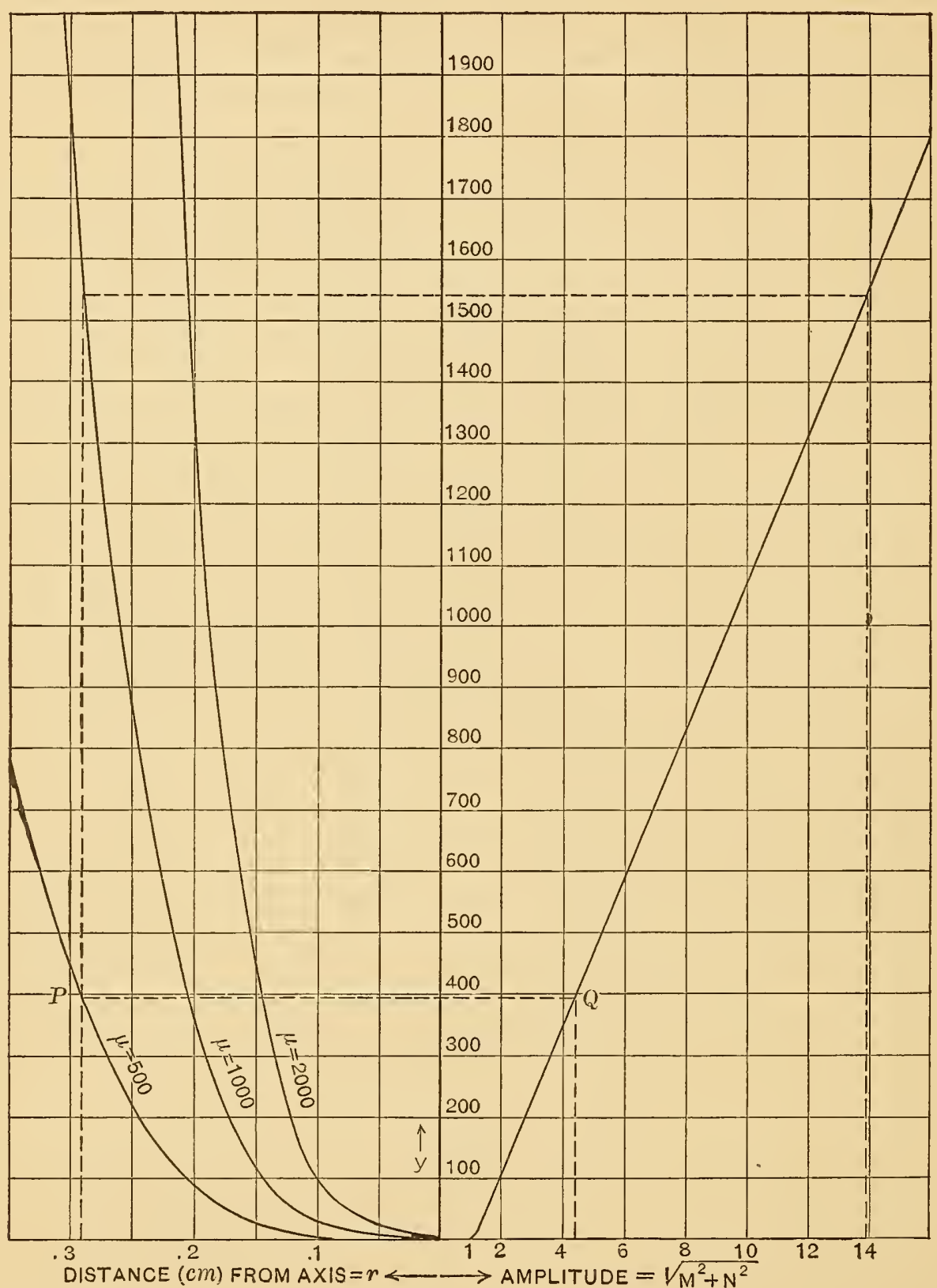

Fig. 25.-Theoretical curves based on Heavisides's formula showing how the amplitude of an alternating magnetic fux varies over the cross section of a round rod for various assumed values of the permeability.

holding it in the earth's field and striking it a sharp blow with a hammer. A soft iron wire placed in the terrestrial field and gently 
rubbed takes up a magnetization far greater than its permeability determined in the usual way would indicate. Equally gentle rubbing will remove the major portion of the most intense residual magnetization. Ewing ${ }^{18}$ has investigated quite thoroughly the effect of intense mechanical disturbances on the magnetic state of a bar of

TABLE XXX.

Showing the increase of induction in soft iron due to very gentle vibration.

\begin{tabular}{c|c|c|c|c}
\hline$H$ & $\begin{array}{c}B \\
\text { Normal }\end{array}$ & $\begin{array}{c}\text { With tapping } \\
\text { W }\end{array}$ & $\begin{array}{c}\text { Increase of } B \text { due } \\
\text { to tapping }\end{array}$ & $\begin{array}{c}\text { Per cent } \\
\text { increase of } B\end{array}$ \\
\cline { 1 - 2 } .2 & 200 & 211 & 11 & 5 \\
.3 & 370 & 395 & 25 & 7 \\
.4 & 600 & 645 & 45 & 7 \\
.6 & 950 & 1018 & 68 & 7 \\
.7 & 1445 & 1542 & 97 & 7 \\
.8 & 2400 & 2525 & 125 & 5 \\
.9 & 3400 & 3535 & 135 & 4 \\
1.0 & 4200 & 4340 & 140 & 3 \\
1.1 & 4850 & 4985 & 135 & 3 \\
1.2 & 5400 & 5525 & 125 & 2 \\
1.3 & 5900 & 6010 & 110 & 2 \\
1.4 & 6350 & 6440 & 90 & 1 \\
1.5 & 6700 & 6770 & 70 & 1 \\
1.6 & 7050 & 7100 & 50 & 1 \\
1.7 & 7350 & 7380 & 30 & 0 \\
1.8 & 7600 & 7620 & 20 & 0 \\
1.9 & 7850 & 7860 & 10 & 0 \\
2.0 & 8100 & 8105 & 5 & 0 \\
\hline
\end{tabular}

Plotted on Fig. 26.

iron. The effect of vibration is to shake in more induction if the magnetic force is acting, and to shake out the residual induction if no magnetic force is acting. The hysteresis loop is contracted and draws in close to the induction curve, which loses its point of inflection and apparently starts out with a maximum permeability which 
steadily decreases. While the increase in permeability is appreciable in moderately strong fields, it is in weak fields that the effect is most striking. In the case recorded by Ewing and which we have no

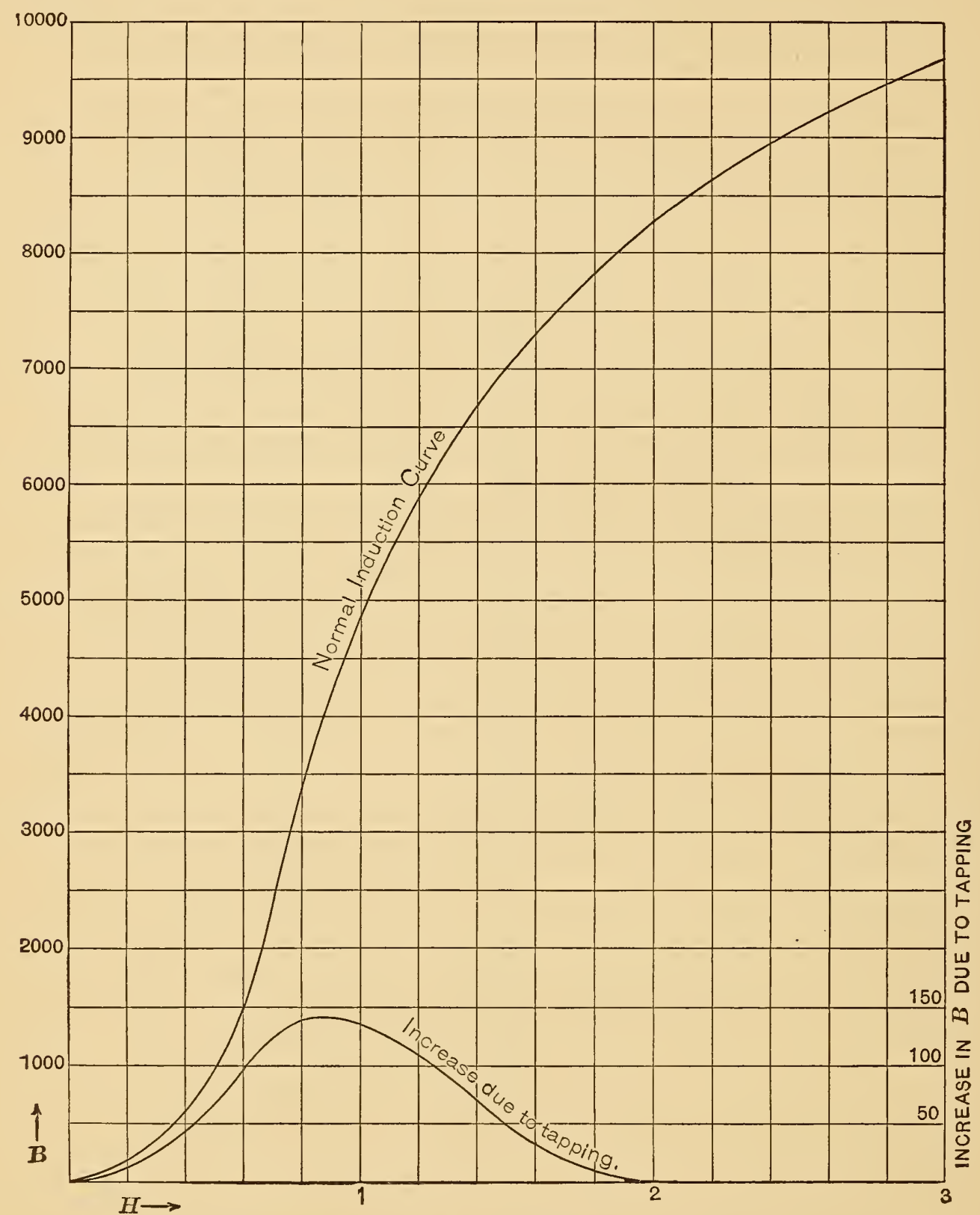

Fig. 26.- Showing the infuence of gentle vibrations on the inductions in soft iron. (Numerical data in Table XXX.)

reason to suppose was unusual the permeability as measured during a mechanical vibration assumed the enormous value of 80,000 . These same phenomena are observed in hard iron and steel, but to a much less degree. 
GENTLE VIBRATIONS.

The following experiment was undertaken to determine whether the ordinary vibrations of a building containing moving machinery, such as a reciprocating engine, affect the values obtained in a magnetic test. The gong was removed from a small electric bell and the electromagnet mounted so that the hammer might strike against one end of a slender wooden rod 50 centimeters long, the other end of which rested against one of the yokes containing the test specimen. The wooden rod was interposed partly to deaden the effect of the blows delivered by the hammer and partly to permit the removal of the electromagnet to such a distance that its field would not react on the test specimen. To diminish the vibration still further a piece of soft rubber tubing was slipped over the hammer and another piece fastened to the end of the wooden rod. To insure a separation of the natural vibrations of the building from those of the experiment, the magnetic system under test was mounted on several layers of heavy wool felt. As nearly as could be estimated, by placing the hand alternately on the apparatus under test and on the table, the tapping device gave a disturbance of the same order of of magnitude as the vibration of the building. With this arrangement the data of Table XXX were obtained. The first column gives the magnetizing force; the second, the value of the induction after the iron had been subjected to many reversals to insure a cyclic state; the third, the induction obtained while the iron was under vibration; the fourth, the increase due to vibration, and the last column gives the proportional increase. These data are shown graphically in Fig. 26. It is to be noticed that the effect of vibration, both in absolute value and in percentage, passes through a maximum at approximately the point where the differential permeability is a maximum. The maximum value of 7 per cent in the disturbing effect shows that for accurate work it is necessary to protect the apparatus from vibration. Even the slamming of a door at one time and the dragging of a heavy box along the floor at another have modified the induction by a measurable amount.

Small changes in the intensity of the mechanical disturbance were accompanied by correspondingly small changes in magnetism, so that the curve may be taken as that characteristic of small disturbances. 
To investigate more fully the nature of the effect of these mechanical vibrations the specimen was subjected without vibrations to many reversals of a small force until a cyclic state ensued and the ballistic throw on reversal noted. Next, without altering the current, the vibrator was started. This produced a small deflection. The return reversal was then taken without vibration, then another reversal without vibration, then the tapping, and lastly a reversal while the tapping was in progress. The following table shows the results:

\begin{tabular}{llc}
\multicolumn{2}{c}{ Operations performed } & Galvanometer \\
Magnetic. & Mechanical. & Deflection. \\
Reversal. & None. & +7.00 \\
None. & Tapping. & +.23 \\
Reversal. & None. & -7.28 \\
Reversal. & None. & +7.00 \\
None. & Tapping. & +.29 \\
Reversal. & Tapping. & -7.47
\end{tabular}

The small deflection produced by tapping after a reversal had been made was the result of the first few taps, for an instantaneous closing of tapping circuit produced the full effect which was not increased by repeated and continued tapping. It is also characteristic that a single reversal wipes out the effect of provious tapping so that the second reversal is normal. What occurs mi $f$ be shown more clearly by the use of Fig. 28. Here A represents the magnetic state before the first throw. The first reversal brings the state point to B. Tapping runs it up to D. A reversal without tapping brings it back to A. Tapping runs it down to C. Reversal with tapping carries it to $\mathrm{D}$. So that simple reversals cause the state point to traverse cycle AB. Reversals with taps give cycle CD. Reversals followed by taps give cycle CBDA.

A comparison of these effects with those noted under the study of viscosity shows a close connection between the creeping up of the induction due to viscosity and the same thing for tapping. Both these phenomena may be accounted for by assuming a frictional force opposing the movements of the molecular magnets. It was found that such gentle vibrations as these were of little help in demagnetizing either when used alone or with current. 
For higher inductions the effect of tapping was appreciable but negligible.

The persistance of previous polarization, as modified by a slight tapping, is shown in the data of Table XXXI. Here the iron has been polarized and then subjected to reversals of a small force till a cyclic condition exists. A few taps raise the apparent induction, which then decreases to a second constant value somewhat higher

TABLE XXXI.

Showing the demagnetizing effect of tapping combined with repeated reversals.

\begin{tabular}{|c|c|c|c|c|}
\hline Number of reversal & \multicolumn{4}{|c|}{ Galvanometer deflection } \\
\hline 1 & 9.80 & & & \\
\hline 2 & 6.19 & & & \\
\hline 3 & 5.99 & & & \\
\hline 4 & 5.81 & & & \\
\hline 6 & 5.71 & & & \\
\hline 8 & 5.66 & & & \\
\hline 10 & 5.62 & & & \\
\hline 20 & 5.62 & & & \\
\hline 100 & 5.61 & & & \\
\hline 200 & 5.62 & & & \\
\hline 202 & 5.80 & after gentl & pping for & 15 seconds \\
\hline 204 & 5.86 & " " & " " & 1 minute \\
\hline 206 & 5.89 & " & " $"$ & 2 " \\
\hline 306 & 5.89 & " 6 & " 6 & 100 cycles \\
\hline 406 & 5.69 & & & \\
\hline 500 & 5.69 & & & \\
\hline 1800 & 5.69 & & & \\
\hline
\end{tabular}

than the first. The gentle vibration has therefore removed a portion of the residual induction, but is not an efficient means of demagnetization.

From the preceding experiment it appears desirable that the magnetic system be protected from small mechanical vibrations. A pad of felt half an inch thick accomplishes this very nicely for all ordinary cases. 


\section{INFLUENCE OF TEMPERATURE.}

It is well known that for a small rise of temperature above room values the permeability of iron increases for low inductions and

\section{TABLE XXXII.}

Showing the induction at various temperatures of an annealed transformer iron ring.

\begin{tabular}{|c|c|c|c|c|c|c|}
\hline$H$ & $\begin{array}{c}B_{\mathrm{s}} \\
t=8\end{array}$ & $\begin{array}{c}B_{=6.6} \\
t=26.5\end{array}$ & $\underset{t=48}{B_{48}}$ & $B_{48}-B_{8}$ & $\frac{B_{48}-B_{8}}{40}$ & $\frac{B_{48}-B_{8}}{40 B_{8}}$ \\
\hline 0.5 & 473 & 495 & 516 & 43 & +1.1 & .0023 \\
\hline 1.0 & 3317 & 3479 & 3621 & 304 & +7.6 & .0023 \\
\hline 2.0 & 8810 & 8970 & 9170 & 360 & +9.0 & .0010 \\
\hline 3.0 & 11560 & 11700 & 11870 & 310 & +7.7 & .0007 \\
\hline 5.0 & 14330 & 14460 & 14510 & 180 & +4.5 & .0003 \\
\hline 10.0 & 16440 & 16440 & 16440 & 0 & 0 & .0000 \\
\hline 15.0 & 17150 & 17160 & 17180 & 30 & 0 & .0000 \\
\hline
\end{tabular}

See Fig. 27.

TABLE XXXIII.

Showing the inductions at various temperatures of an unannealed transformer iron ring.

\begin{tabular}{r|r|r|r|r|r}
\hline$H$ & $\begin{array}{r}B_{12} \\
H=12\end{array}$ & $\begin{array}{r}B_{47} \\
t=47\end{array}$ & $B_{47}-B_{12}$ & $\frac{B_{47}-B_{12}}{35}$ & $\frac{B_{47}-B_{12}}{35} B_{12}$ \\
\cline { 2 - 3 } 0.5 & 290 & 306 & 16 & .5 & .0017 \\
1.0 & 1081 & 1148 & 67 & 1.9 & .0018 \\
2.0 & 4670 & 4800 & 130 & 3.7 & .0008 \\
3.0 & 7225 & 7310 & 85 & 2.4 & .0003 \\
5.0 & 10290 & 10340 & 50 & 1.4 & .0001 \\
10.0 & 13930 & 12920 & -10 & -.3 & .0000 \\
15.0 & 15630 & 15590 & -40 & -1.1 & .0000 \\
\hline
\end{tabular}

See Fig. 27.

decreases for high inductions. At higher temperature this temperature coefficient is always negative and increases rapidly with the temperature, until finally the iron becomes practically nonmagnetic 
at some temperature between $690^{\circ} \mathrm{C}$. and $870^{\circ} \mathrm{C}$. For the ordinary fluctuations of room temperature very little experimental work has been done.

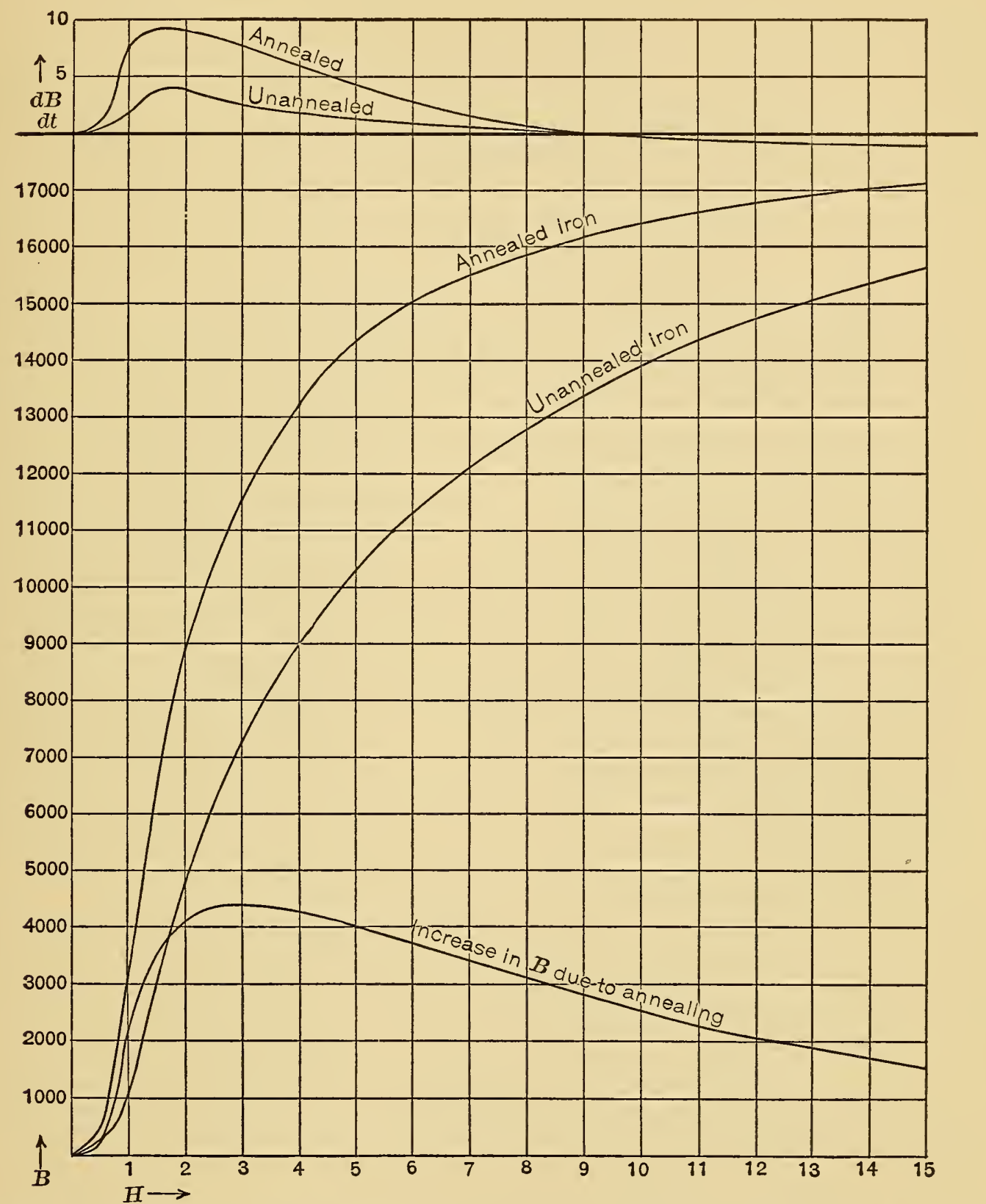

Fig. 27.-Showing the effect of temperature and annealing on the induction in soft iron.

(Numerical data in Tables XXXII, XXXIII, and XXXIV.)

Ewing, ${ }^{19}$ from data obtained at $7^{\circ}$ and $100^{\circ} \mathrm{C}$., concluded that atmospheric fluctuations need not be considered in magnetic meas-

${ }^{19}$ Magnetic Induction, etc., p. 178.

II $737-07-7$ 
urements. Permanent magnets such as are used in magnetic surveys and in electrical measuring instruments have a negative temperature coefficient of the order of .05 per cent. Whether or not the temperature coefficient is of sufficient importance to warrant its consideraation is a question of the degree of accuracy desired. It seemed worth while therefore to determine the temperature coefficients of a few specimens over the atmospheric range. Four different specimens of transformer iron were examined at different temperatures. A portion of the data is shown numerically in Tables XXXII,

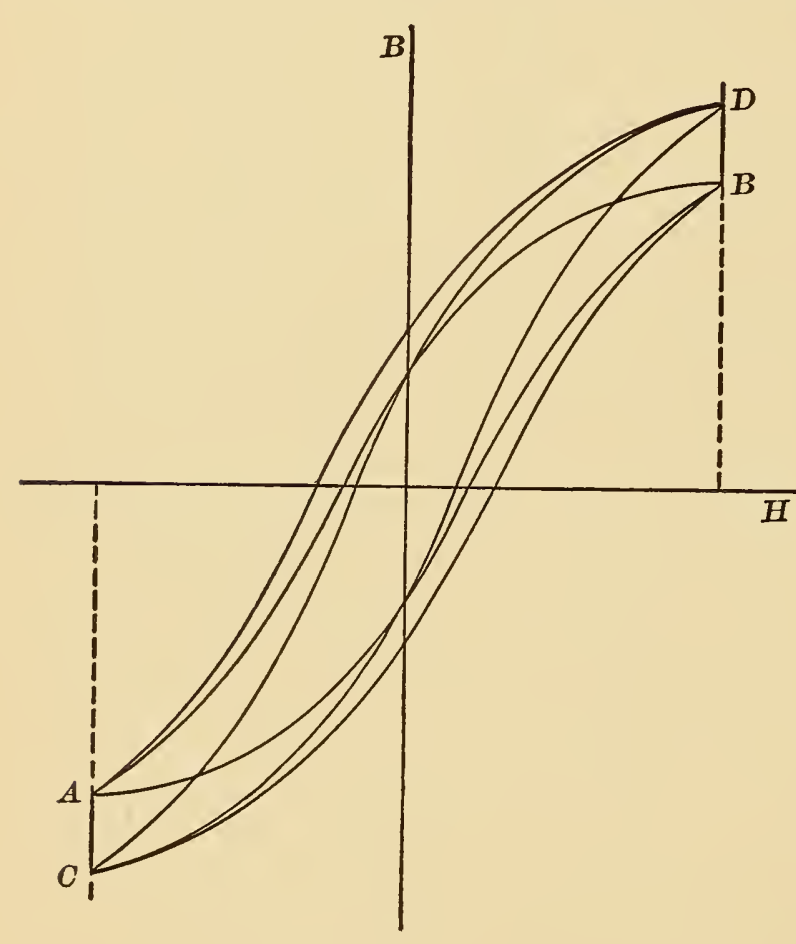

Fig. 28.- Ideal curve to illustrate the effect of vibration on the apparent induction.
XXXIII, and XXXIV, and graphically in Fig. 27. These specimens were two bundles of stamped transformer iron rings about to centimeters in diameter, cut from the same sheet. One was annealed and the other not. From the data and curves the following observations may be made:

(I) The change in induction per $I^{\circ}$ C. rise in temperature is greatest in the neighborhood of the maximum permeability.

(2) The temperature coefficient is greater for the annealed than for the unannealed iron.

(3) The high value of this maximum temperature coefficient (onefourth per cent) shows that temperature must be taken account of if an accuracy of I per cent is to be attained.

(4) The increase of induction due to annealing is greatest near the point of maximum permeability.

Throughout this work one is impressed with the varying sensitiveness with which the different parts of the $B-H$ curve are influenced by slight changes in the conditions. All those elements, such as polarization, temperature, viscosity, or vibrations, which 
tend to modify the apparent induction produce their greatest effects in the steep part of the induction curve. Beyond the critical point the induction is independent of previous magnetization and but lightly influenced by vibrations and temperature changes. Greater sensitiveness is noticed in the soft irons than in the hard ones. The difficulties of permeability measurements, therefore, are found in the earlier part of the induction curve, and it is here that the greatest care must be taken and the largest tolerance allowed.

\section{TABLE XXXIV.}

Showing the effect of annealing on the induction in transformer iron (Temperature $10^{\circ} \mathrm{C}$ ). Calculated from Tables XXXII and XXXIII.

\begin{tabular}{r|r|r|r|r}
\hline$H$ & Annealed $=B_{a}$ & Unannealed $=B_{u}$ & $B_{a}-B_{u}$ & $\frac{B_{a}-B_{u}}{B_{a}}$ \\
\cline { 2 - 3 } 0.5 & 475 & 289 & 186 & .39 \\
1.0 & 3332 & 1078 & 2254 & .67 \\
2.0 & 8830 & 4660 & 4170 & .47 \\
3.0 & 11580 & 7220 & 4360 & .38 \\
5.0 & 14340 & 10290 & 4050 & .28 \\
10.0 & 16440 & 13930 & 2510 & .15 \\
15.0 & 17150 & 15630 & 1520 & .09 \\
\hline
\end{tabular}

See Fig. 27.

\section{THE BEST METHOD OF PROCEDURE.}

In view of evidence offered in the preceding pages the following rule may be outlined as the best (ballistic) method of procedure in magnetic testing:

The magnetic system, consisting of the test pieces and the connecting yokes, should be mounted with its plane perpendicular to the earth's field. If necessary the system should be protected from mechanical vibrations by means of a pad of felt, or something equivalent. If an accuracy of I per cent in the steep part of the $B-H$ curve is desired the temperature should be kept at some standard temperature (e. g., $20^{\circ} \mathrm{C}$.) constant to $\mathrm{I}^{\circ}$ or $2^{\circ} \mathrm{C}$. It is not feasible to apply a temperature coefficient correction on account of the difficulty in getting its value. 
The demagnetization should be accomplished by a current reversed at the rate of approximately one cycle per second, while gradually diminished in such a way that the rate of decrease of the induction is as nearly as may be uniform. An ammeter in circuit and a rough estimate of the shape of the $B-H$ curve will enable one to regulate the rate of decrease of current with sufficient exactness. The initial demagnetizing current should be sufficient to carry the induction beyond the knee of the $B-H$ curve, ${ }^{20}$ and the final current should be not greater than the smallest magnetizing current to be used.

The full demagnetization may be accomplished in about ninety seconds.

Now apply the lowest magnetizing force desired and reverse at the same speed as in demagnetizing. At intervals get a ballistic deflection. Continue this until two deflections about twenty-five reversals apart show only a negligible difference ${ }^{21}$. This final deflection is the normal induction.

Without demagnetizing again, apply the next larger magnetizing force and reverse as before. Continue in this way till all the required points on the curve have been obtained.

In closing I wish to acknowledge my indebtnesss to Professor Rosa, under whose supervision the work has been done, for his continued advice and suggestions.

Washington, September 3, I907.

${ }^{20}$ Without going to the trouble of a preliminary test an initial demagnetizing force of 15 units may safely be assumed for all specimens of soft iron.

${ }^{21}$ Several hundred reversals may be required in the steep part of the $B-H$ curve, while half a dozen are sufficient in the upper portions. 